NASA CONTRACTOR REPOR T

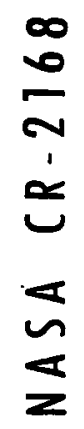
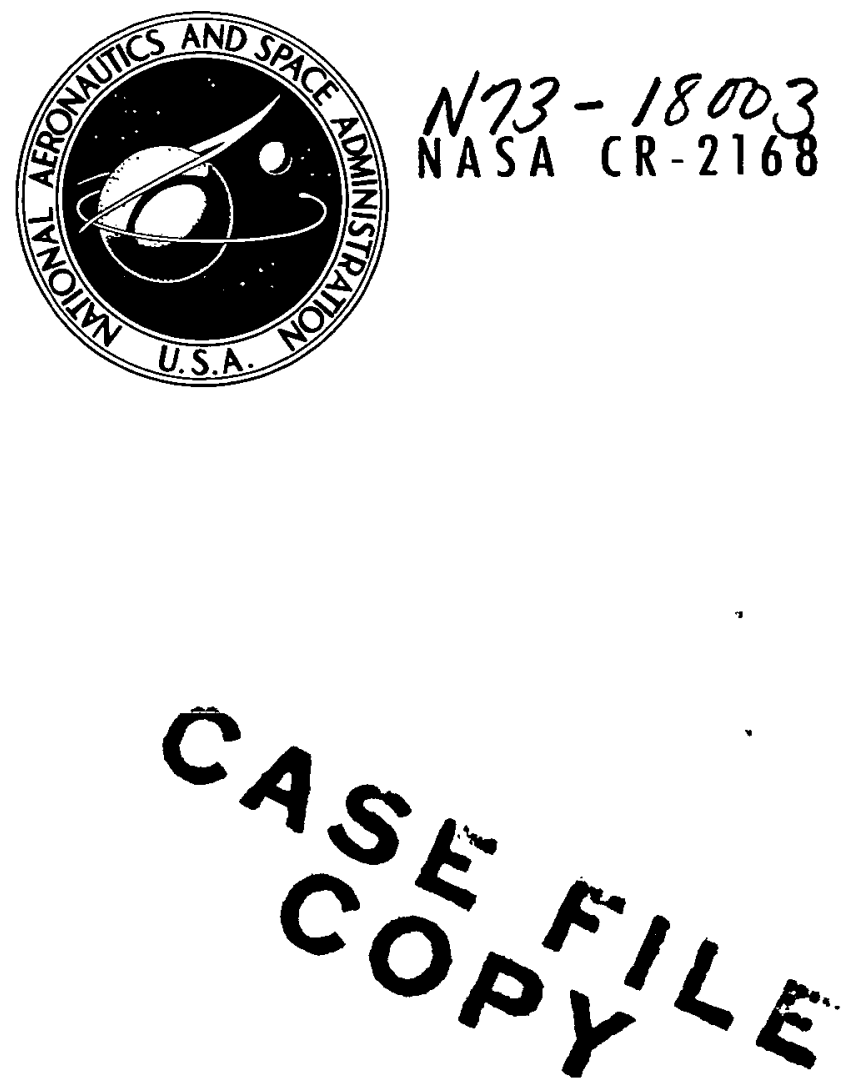

DEVELOPMENT AND APPLICATIONS

OF SUPERSONIC UNSTEADY

CONSISTENT AERODYNAMICS FOR

INTERFERING PARALLEL WINGS

by Kari Appa and G. C. C. Smith

Prepared by

BELL AEROSPACE COMPANY

Buffalo, N.Y. 14240

for Langley Research Center

NATIONAL AERONAUTICS AND SPACE ADMINISTRATION - WASHINGTON, D. C. - MARCH 1973 


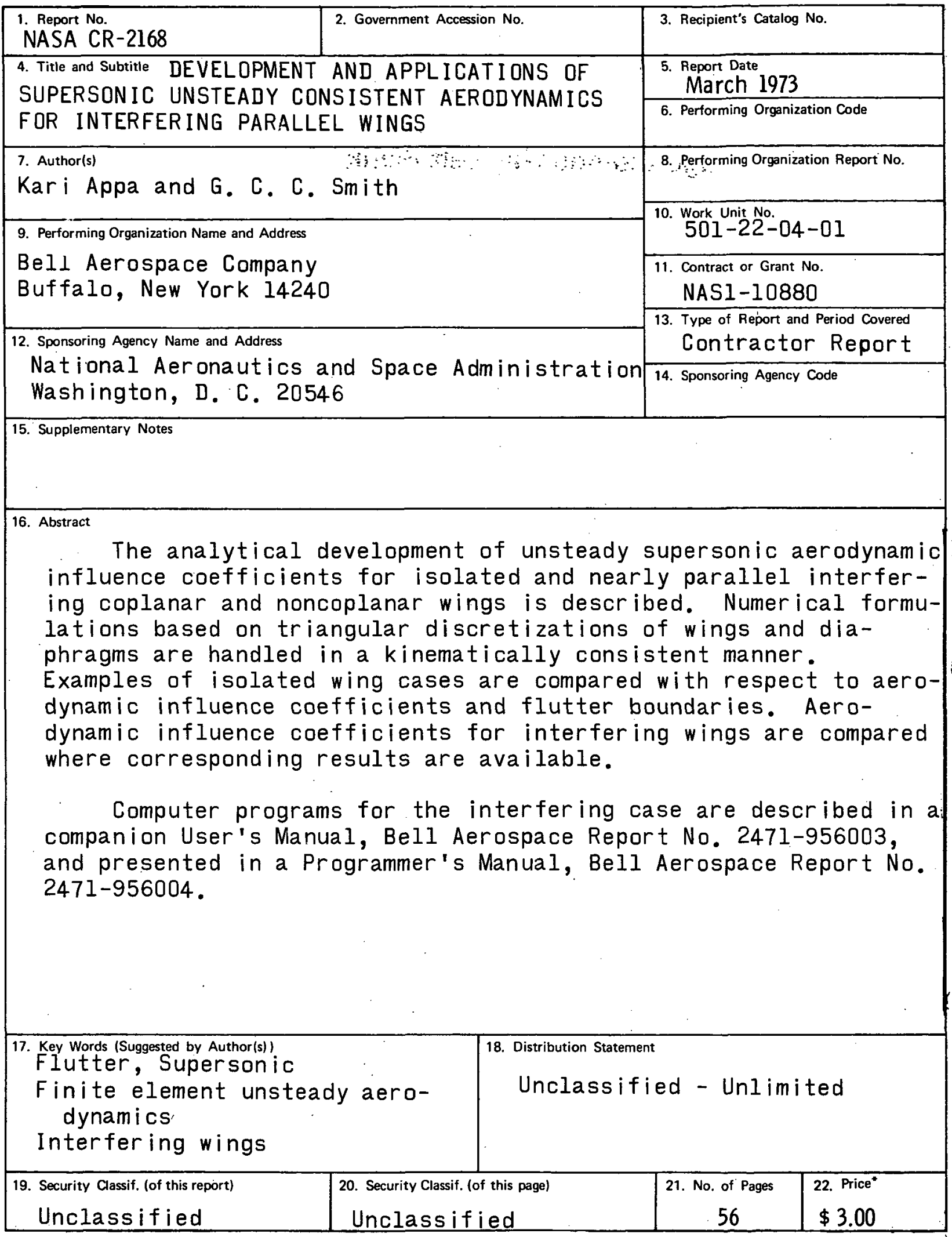

"For sale by the National Technical Information Service, Springfield, Virginia 22151 


\section{FOREWORD}

This report describes developments in the analy tical determination of unsteady supersonic aerodynamics for a class of interfering wings using a triangular element representation of wings and diaphragms.

The work was accomplished by Bell Aerospace Company under Contract NAS 1-10880 with the National Aeronautics \& Space Administration, Langley Research Center, Hampton, Virginia. G.C.C. Smith was Program Manager and Dr. Kari Appa was the Principal Investigator. A. A. Paine wrote the associated computer programs (Ref 28 ).

The following program documents are relevant to this report:

USER'S MANUAL - NASA CR-112184

PROGRAMMER'S MANUAL - NASA CR-112185

The authors acknowledge permission from the Air Force to publish data from References 11 and 19. 


\section{CONTENTS}

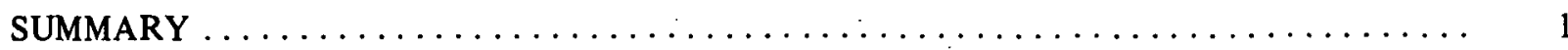

INTRODUCTION $\ldots \ldots \ldots \ldots \ldots \ldots \ldots \ldots \ldots \ldots \ldots \ldots \ldots \ldots \ldots \ldots \ldots \ldots$

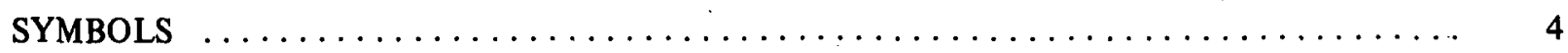

DEVELOPMENT OF THE METHOD $\ldots \ldots \ldots \ldots \ldots \ldots \ldots \ldots \ldots \ldots \ldots \ldots \ldots \ldots \ldots \ldots$

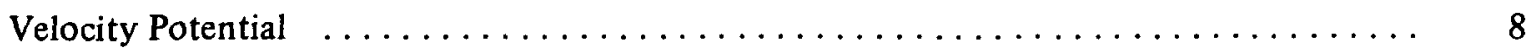

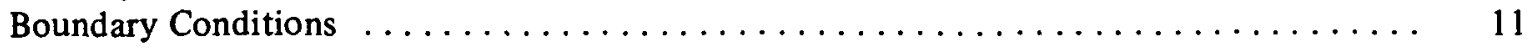

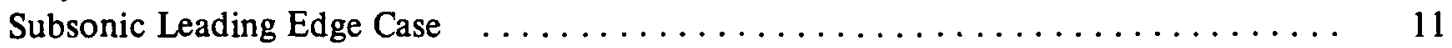

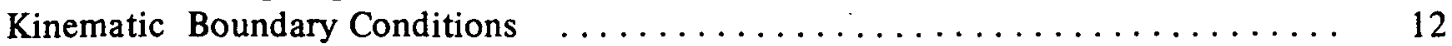

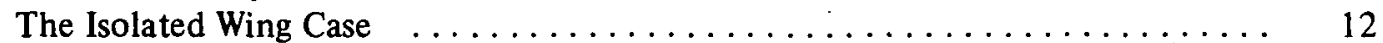

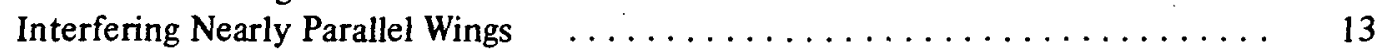

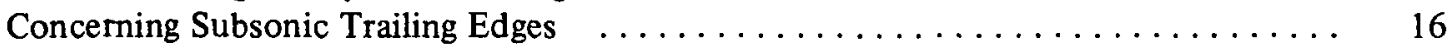

Consistent Nodal Forces . . . . . . . . . . . . . . . . . . . . . . . . . . . . . 17

Generalized Forces $\ldots \ldots \ldots \ldots \ldots \ldots \ldots \ldots \ldots \ldots \ldots \ldots \ldots \ldots \ldots$

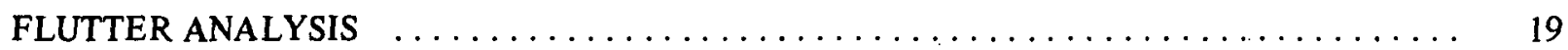

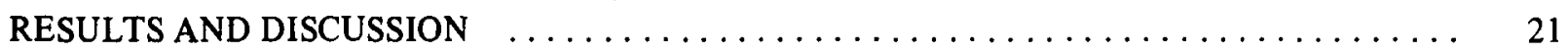

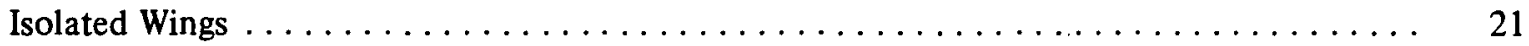

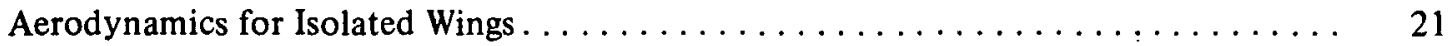

Flutter Solutions for Isolated Wings (NASA HT-7 Example) $\ldots \ldots \ldots \ldots \ldots \ldots \ldots$

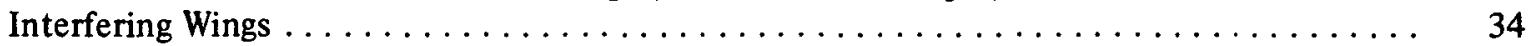

Generalized Aerodynamics (Interfering Wing-Tail Example) $\ldots \ldots \ldots \ldots \ldots \ldots$

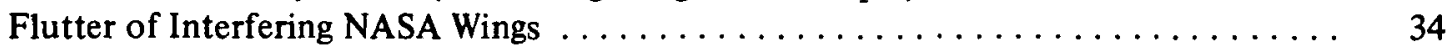

CONCLUSIONS AND RECOMMENDATIONS $\ldots \ldots \ldots \ldots \ldots \ldots \ldots \ldots \ldots \ldots \ldots \ldots$

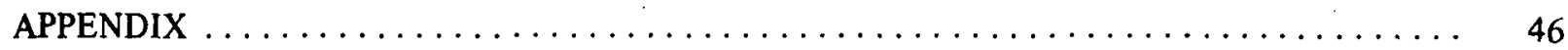

Velocity Potential - Isolated Wing $\ldots \ldots \ldots \ldots \ldots \ldots \ldots \ldots \ldots \ldots \ldots \ldots \ldots \ldots$

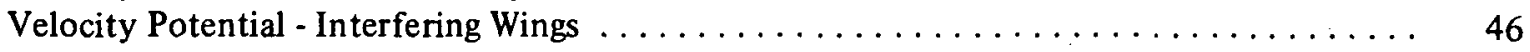

Downwash Integrals . . . . . . . . . . . . . . . . . . . . . . . 49

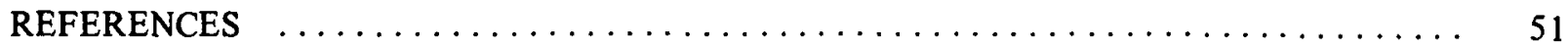




\section{ILLUSTRATIONS}

Figure

Page

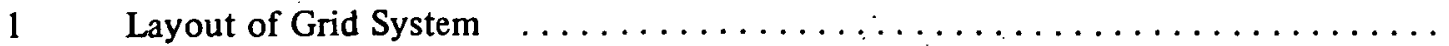

2 Layout of Grid System - 2 Wings

3 Velocity Potential Distribution on a Cropped Delta Wing at Constant

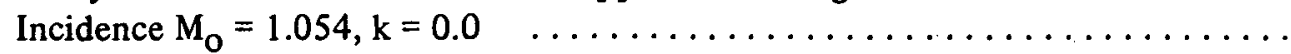

4 Real Part of Velocity Potential on a Cropped Delta Wing in Translation .......... 30 29

Vector Plot of Aerodynamic Generalized Coefficients $\mathbf{Q}_{\mathrm{ij}}$ for a Cropped Delta Wing

Vector Plot of Aerodynamic Generalized Coefficients $Q_{i j}$ for a Rectangular Wing of Aspect Ratio 2

Flutter Boundary in Terms of the Stiffness - Altitude Parameter and Ratio of Flutter Frequency to the Second Natural Frequency versus M for

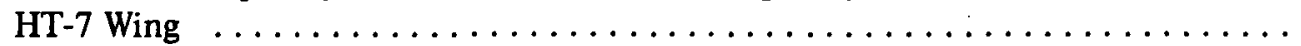

Configuration of Triangular Wing - Tailplane $\ldots \ldots \ldots \ldots \ldots \ldots \ldots \ldots \ldots$ $M_{0}=1.6$

\section{TABLES}

Number

2 Comparison of Aerodynamic Generalized Coefficients $Q_{i j}$ for a

3 Comparison of Aerodynamic Generalized Coefficients $Q_{i j}$ for Rectangular Wing of Aspect Ratio 2

Comparison of Aerodynamic Generalized Coefficients $\mathrm{Q}_{\mathrm{ij}}$ for AGARD Swept

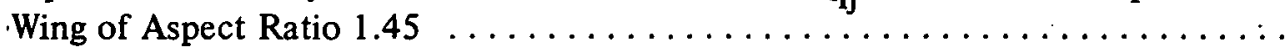

Comparison of Aerodynamic Generalized Coefficients $Q_{i j}$ for AGARD Swept

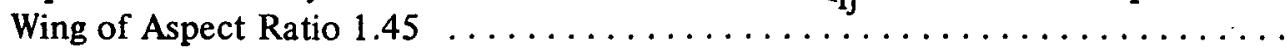

Comparison of Aerodynamic Generalized Coefficients $\mathbf{Q}_{\mathrm{ij}}$ for AGARD Swept

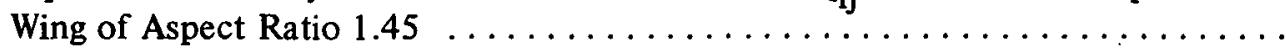

Comparison of Aerodynamic Generalized Coefficients $Q_{i j}$ for AGARD Swept

Wing of Aspect Ratio 1.45

Comparison of $I m$. Part of Generalized Damping Coefficients $Q_{i j}$ for Delta

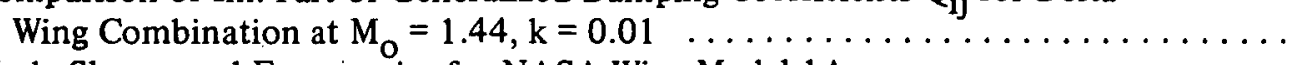

9A Mode Shapes and Frequencies for NASA Wing Model $1 \mathrm{~A} \ldots \ldots \ldots \ldots \ldots \ldots$

9B Mode Shapes and Frequencies for NASA Wing Model 2A 


\title{
DEVELOPMENT AND APPLICATIONS OF \\ SUPERSONIC UNSTEADY CONSISTENT \\ AERODYNAMICS FOR INTERFERING \\ PARALLEL WINGS
}

\author{
by \\ Kari Appa * and G. C. C. Smith ${ }^{+}$ \\ Bell Aerospace Company \\ Division of Textron Inc.
}

\section{SUMMARY}

The analytical development of unsteady supersonic aerodynamic influence coefficients, (AIC's), for isolated and nearly parallel interfering coplanar and noncoplanar wings is described. Numerical formulations based on triangular discretizations of wings and diaphragms are handled in a kinematically consistent manner. Examples of isolated wing cases are compared with respect to AIC's and flutter boundaries. AIC's for interfering wings are compared where corresponding results are available.

Computer programs for the interfering case are described in a companion User's Manual, NASA CR-1 12184, and presented in a Programmer's Manual, NASA CR-112185.

\section{INTRODUCTION}

The evaluation of aeroelastic effects requires accurate determination of oscillatory aerodynamic, stiffness and inertia properties of a flight vehicle. Stiffness and inertia properties of geometrically complex structures may be computed to a high degree of accuracy using modern finite element methods. The determination of unsteady aerodynamic forces in various flow regimes on the other hand, involves more complex differential equations, and their integral solution equivalents. Satisfactory solutions, analytical for simple planforms, and numerical for more complex planforms have evolved for isolated planar wings. Much effort has been devoted to more complex situations involving intersecting surfaces, interfering surfaces, dihedralled surfaces, and wing-body interference. The summary papers of References 1 and 2 attest to the intensive interest and efforts applied.

Garrick and Rubinow (Ref 3) pioneered the development of solutions to such boundary value problems by the superposition of elementary solutions of the nature of pulsating acoustic sources distributed on the boundaries, from which have developed many techniques discussed in the literature. References 1 and 2 indicate that integration of the differential/integral equations for practical and increasingly complicated wing and wing-body configurations is a significant problem even with present day computational facilities. Therefore, numerical integration methods are continually being modified and improved.

* Chief, Dynamic Analysis

+ Chief Engineer, Structural Dynamics 
In supersonic flow, numerical integration procedures have been based on the representation of domains of dependence in terms of discrete "elements" of various types in each of which the downwash has generally been approximated as a constant.

These types include

- $\quad$ square boxes (e.g., Pines, Dugundji and Neuringer, (Ref 4)) in which the sides are parallel and normal to the free stream

- $\quad$ characteristic boxes (e.g., Smith (Ref 5) and Zartarian, Hsu and Voss (Ref 6)) in which parallelogram elements have their sides parallel to the Mach lines

- rectangular ("Mach") boxes (e.g., Li, Ref 7) such that the box diagonals are parallel to the Mach lines.

Zartarian and Hsu (Ref 8 ) made extensive studies on the application of rectangular, characteristic and Mach box methods, and discussed various working rules for the application of the Mach box method.

Ashley (Ref 9) described the application of superposition methods to interfering surfaces and the use of Mach box methods for intersecting planes.

Moore and Andrew (Ref 10) and Donato and Huhn (Ref 11) developed computer programs to calculate the velocity potentials and generalized forces for isolated, interfering and intersecting planes. Stark (Ref 12) contributed very significantly to the evaluation of downwash terms along a subsonic leading edge in the characteristic box approach.

The general approaches listed above have at least two obvious factors leading to inaccuracies in numerical computations

- the planform and associated diaphragm boundaries cannot be well represented with elements tied to characteristic or flow directions

- the approximation of constant downwash within an element.

While both inaccuracies can be alleviated by the use of a larger number of smaller elements, it is obvious that this is at the expense of a large increase in the number of equations to be handled, and will result in rapidly increasing computational effort.

Appa and Smith in References 13 and 14 have discussed a different approach to planform and diaphragm discretization and numerical procedures which have the following advantages over the methods referred to above:

- constancy of the wing grid system at all Mach numbers

- continuous distribution of downwash terms across element boundaries

- well-represented wing and diaphragm boundaries

- flexibility in the choice of diaphragm elements 
- consistent aerodynamic forces via the principle of virtual work

- convenient aeroelastic formulation for flutter synthesis problems (e.g., optimization)

The following sections relate to analytical developments and computer applications for such a method in the case of isolated and interfering nearly parallel coplanar and noncoplanar wings at supersonic Mach numbers.

Results for unsteady aerodynamic forces from the present method are compared with published data from other methods.

Additionally, the method is applied to flutter of planar isolated and interfering wings and compared (for isolated wings) to experimental results.

The general intent of the work is to illustrate the potential for more economic and accurate determination of supersonic unsteady aerodynamics particularly for complex configurations.

An operational computer program which was developed in the course of the work has been used on IBM 360/65 and CDC6600. 


\section{SYMBOLS}

$\mathbf{A}^{\prime}, \mathbf{B}^{\prime}, \mathbf{A}, \mathbf{B} \quad$ Element and system pressure matrices

a

$a_{0}$

$a_{u}, a_{\ell}$

$\mathrm{b}_{\mathrm{u}}, \mathrm{b}_{\ell}$

$\mathrm{b}_{\mathrm{o}}$

c

F

I

$\mathbf{k}=\frac{\omega \ell}{U}$

$\hat{\mathbf{k}}$

K

$\ell$

$\mathbf{M}$

$\mathrm{M}_{\mathrm{o}}$

$\overrightarrow{\mathrm{n}}$

n

$\mathrm{N}$

$\overline{\mathbf{N}}$

p

p
A Boolean matrix describing topological connections of the elements in the structure

Speed of sound in free stream

Slopes of the upper and lower sides of a triangle

Constants in the equations for upper and lower sides of a triangle

Semichord (as in Ref. 21)

Wing chord, Figures 3, 4, 5

Kernel, defined by equation (5)

Integrals; also unit matrix

Reduced frequency

$=\frac{\mathrm{kM}^{2}}{\beta^{2}}$

Stiffness matrix

Reference length

Mass matrix

Mach number

Unit normal vector

Number of degrees of freedom

Number of terms in interpolation or modal series

Summation variable

Pressure

Nodal force vector 


\section{SYMBOLS (CONT)}

$\mathbf{q}$

$\mathrm{q}_{\mathrm{o}}$

$\mathrm{Q}, \widetilde{\mathrm{Q}}$

S

r, $\mathrm{S}$

t

$\mathbf{T}$

U

w

W

$\widetilde{\mathbf{W}}$

$\mathrm{x}, \mathrm{y}, \mathrm{z}$

$\overline{\mathrm{x}}, \overline{\mathrm{z}}$

$X=(x, y, z)$

$\bar{Z}(x, y, t)$

$Z(x, y)$

$\alpha$

$\beta$

$\Gamma, \widetilde{\Gamma}$

$\delta$

$\bar{\eta}$

$\lambda$

$\bar{\lambda}$
Displacement vector

Dynamic pressure, $q_{0}^{*}$ a reference pressure $=1 / 2 \rho_{0}^{*} a_{0}^{* 2} M_{0}^{2}$

Generalized aerodynamic coefficients, discrete and interpolated, respectively

Surface of integration

Hyperbolic radii, Eqn (6)

Dimensional time

Transformation matrix

Flight speed

Downwash velocity

Induced downwash influence coefficient matrix

Virtual work

Dimensionless rectangular coordinates

$x$ and $z$ coordinates of apex of tailplane (see Fig. 9)

Position vector of receiving point

Displacement in space-time, nondimensional, referred to $\ell$

Displacement amplitude (nondimensional)

Damping rate; (see $\lambda$ )

$=\left(M_{0}^{2}-1\right)^{1 / 2}$

Transformation Matrices Eqns (19), (38)

$=\mathrm{q}_{\mathrm{o}}^{*} / \mathrm{q}_{\mathrm{O}}$, dynamic pressure ratio

A column vector of generalized coordinates

$=\alpha+i \omega$

$\frac{\lambda \ell}{U}=\frac{\alpha \ell}{U}+i \frac{\omega \ell}{U}$, a complex reduced frequency 


\section{SYMBOLS (CONT)}

$\mu$

$\mu, \nu$

$\xi, \eta, \zeta$

$\Xi=(\xi, \eta, \zeta)$

$\rho$

$\rho$

$\sigma$

$\sigma$

$\varphi$

$\varnothing$

$\Phi$

$x$

$\psi$

$\Psi$

$\omega$

$\tilde{\omega}$

$\Omega$

Subscripts

cr

$\mathrm{i}, \mathrm{j}$

$\ell, m$

$\mathbf{n}, \mathbf{r}$

$\mathrm{Re}, \mathrm{Im}$
Ratio of structural mass to air mass

Defined by Eqn. (A7) .

Dimensionless running coordinates in the fore Mach cone

Position vector of source in the fore Mach cone

Density of air

Kinematic displacement vector of an element

Source strength (scalar)

A column vector of source strength at nodes of elements, and the complete system

Velocity Potential - a scalar

Column Vector of Velocity potential

Element V.I.C. Matrix relating velocity potential to displacement for isolated wings, and to source strength for interfering wings (see Eqns. 11 and A-5 respectively)

Transformation Matrix of Natural Modes

Defined in Eqn. (A-9)

System source strength to system displacement transformation matrix

Circular frequency, radians per second

$\frac{2}{7} \frac{\omega \mathrm{a}_{\mathrm{O}}}{\mathrm{U}}$ as defined in Ref. 22

An interpolation matrix

Critical

Denote elements or summation variables

Denote modal numbers

Summation variables

Real and imaginary parts 


\section{SYMBOLS (CONT)}

$\mathbf{R}$

S

$\ell, u$

$\eta$

Superscripts

d

L, U

t

w

*

Notation

[ ]

1

[ $]^{t}$

[]$^{-1}$

$\Delta()$

Note:
Reference value

Wake

Lower and upper limits

Derivative with respect to $\eta$

Diaphragm

Lower, Upper

Transpose

Wing

Sea level value (indent on $\rho, \mathrm{q}_{\mathrm{o}}, \mathrm{a}_{\mathrm{o}}$ )

A column vector

A matrix

A diagonal matrix

Transpose of a matrix

Inverse of a matrix

Difference between upper and lower value

In general terms, a lower case symbol represents a continuous variable, a bold-faced symbol with subscript/superscript represents an element nodal value matrix, a bold-faced symbol without subscript represents. a "system" matrix (i.e., that resulting from assembly of all element nodal matrices). This usage applies to $p, q, w$, $\rho, \sigma, \varphi, \psi$, in particular. 


\section{DEVELOPMENT OF THE METHOD}

Detailed derivation and some applications of "finite element" idealizations to the determination of unsteady aerodynamic coefficients appear in References 13 and 14. Application to isolated and interfering planar wings is given in this report. The basic elements used to represent the planform of a wing in a discretized form may be quadrilateral and triangular elements. However, the simpler triangular element forms the basis in this work. The elements can be of different sizes and orientations to "best fit" both wings (independent of Mach number) and diaphragms.

In finite element analysis, functionals within an element are expressed in terms of nodal (discrete) values and derivatives at the nodes by means of interpolation functions. The accuracy of the analysis depends on the degree to which the properties of continuity of the functionals across the element boundaries are satisfied. This is related to the order of appearance of the functional and its derivatives in the integral equation. Since no derivatives of source functionals are involved in the determination of potential, source strength distribution is taken to be expressed linearly within the elements in terms of their nodal values.

Since modal data are also frequently expressed as discrete nodal displacements, the virtual work integrals determined in this work use linearly interpolated potential and modal data to give linearly consistent generalized forces.

\section{Velocity Potential}

The linearized equations of motion in unsteady supersonic flow referenced to a rectangular coordinate system, Figure 1, are given by

$$
\left(1-M_{o}{ }^{2}\right) \frac{\partial^{2} \varphi}{\partial x^{2}}+\frac{\partial^{2} \varphi}{\partial y^{2}}+\frac{\partial^{2} \varphi}{\partial z^{2}}=\frac{2 M_{0}}{a_{0}} \frac{\partial^{2} \varphi}{\partial x \partial t}+\frac{1}{a_{o}{ }^{2}} \frac{\partial^{2} \varphi}{\partial t^{2}}
$$

where $\varphi, M_{0}$ and $a_{0}$ represent the perturbation velocity potential, Mach number and speed of sound respectively. Solutions to equation (1) are sought for harmonic motion of the lifting surface. In many common flutter solution procedures the eigenvalue solutions subsequently determined using assumed real reduced frequency aerodynamics are complex (implying diverging and decaying oscillations) for which the aerodynamics are inconsistent. This suggests, (compare Richardson, Reference 15) the formal determination of aerodynamics for complex exponential motions, which, though not carried through to flutter solutions herein, requires motion of the lifting surface in the form

$$
\bar{Z} \cdot(x, y, t)=Z(x, y) e^{\lambda t}
$$

where $\lambda=(\alpha+i \omega)$,

and $\alpha$ is a damping factor, and $\omega$ the circular frequency of oscillation. (See also Ref. 16).

The deflection $\overline{\mathrm{Z}}$ is related to the source strength through boundary conditions discussed later (see for example, Eqn. 13). 


$$
\varphi(X, t)=-\frac{U l}{\pi} \iint_{S} F(X, \Xi) \sigma(\Xi) \mathrm{d} \xi \mathrm{d} \eta \mathrm{e}^{\lambda t}
$$

where $F(X, \Xi)=\frac{\exp \left(\frac{-l \lambda M_{0}^{2}}{U \beta^{2}}(x-\xi)\right) \cdot \cosh \left(\frac{l \lambda M_{0}}{U \beta^{2}}(r \cdot s)^{1 / 2}\right)}{(r \cdot s)^{1 / 2}}$

is the kernel function,

$$
\left.\begin{array}{l}
r=(x-\xi)-\beta\left[(y-\eta)^{2}+(z-\zeta)^{2}\right]^{1 / 2} \\
s=(x-\xi)+\beta\left[(y-\eta)^{2}+(z-\zeta)^{2}\right]^{1 / 2}
\end{array}\right\}
$$

are hyperbolic radii and $\sigma \cdot(\Xi)$ is the nondimensional source strength distribution. The symbols $X=$ $(\mathrm{x}, \mathrm{y}, \mathrm{z})$ and $\Xi=(\xi, \eta, \zeta)$ denote respectively the vector positions (dimensionless with respect to $\ell)$ at which the velocity potential is evaluated and the influence source strength is situated. The surface integration in equation (4) covers the lifting surface and associated diaphragm regions in the fore Mach cone emerging from X. Generally, closed form integration of (4) is not possible, and numerical integration techniques using various "box" schemes are employed. In the current analysis, the integration area is divided into a number of triangular elements (Figure 1). Summing over all elements the velocity potential within an element i may be written

$$
\varphi\left(X_{i}, t\right)=-\frac{U \ell}{\pi} \sum_{j} \int_{S j} F\left(X_{i} \Xi_{j}\right) \cdot \sigma\left(\Xi_{j}\right) \cdot d \xi d \eta \cdot e^{\lambda t}
$$

where the subscripts $i$ and $j$ denote receiving element $i$ and influencing element $\mathbf{j}$ respectively. By means of interpolation functions $\Omega(\Xi)$ the source strength distribution $\sigma\left(\Xi_{j}\right)$ within an influencing element can be expressed as a linear combination of its nodal values $\sigma_{j}$ as

$$
\sigma\left(\Xi_{j}\right)=\Omega(\dot{\Xi}) \sigma_{j}
$$

where $\Omega$, (see Eqn. A-2) is a row matrix of interpolation functions and $\sigma_{\mathrm{j}}$ is a column vector of nodal values. The nodal values of the source strength for each element can be abstracted from a system source vector $\sigma$ by

$$
\sigma_{j}=a_{j} \sigma
$$

in which $\mathbf{a}_{\mathbf{j}}$ is a Boolean Matrix (Ref 17) related to the topological assembly of the elements. Summing over all the elements in the fore Mach cone region, the velocity potentials at the nodes of the receiving elements are given by

$$
\emptyset_{\mathrm{i}}=-U \ell \sum_{\mathrm{j}} \Phi_{\mathrm{ij}} \mathbf{a}_{\mathrm{j}} \sigma
$$

where $\sigma$ is a nondimensional nodal source vector and

$$
\Phi_{\mathrm{ij}}=\frac{1}{\pi} \iint_{S_{\mathrm{j}}} F\left(\mathbf{X}_{\mathrm{i}}, \Xi_{\mathrm{j}}\right) \Omega(\mathbf{\Xi}) \mathrm{dS}
$$




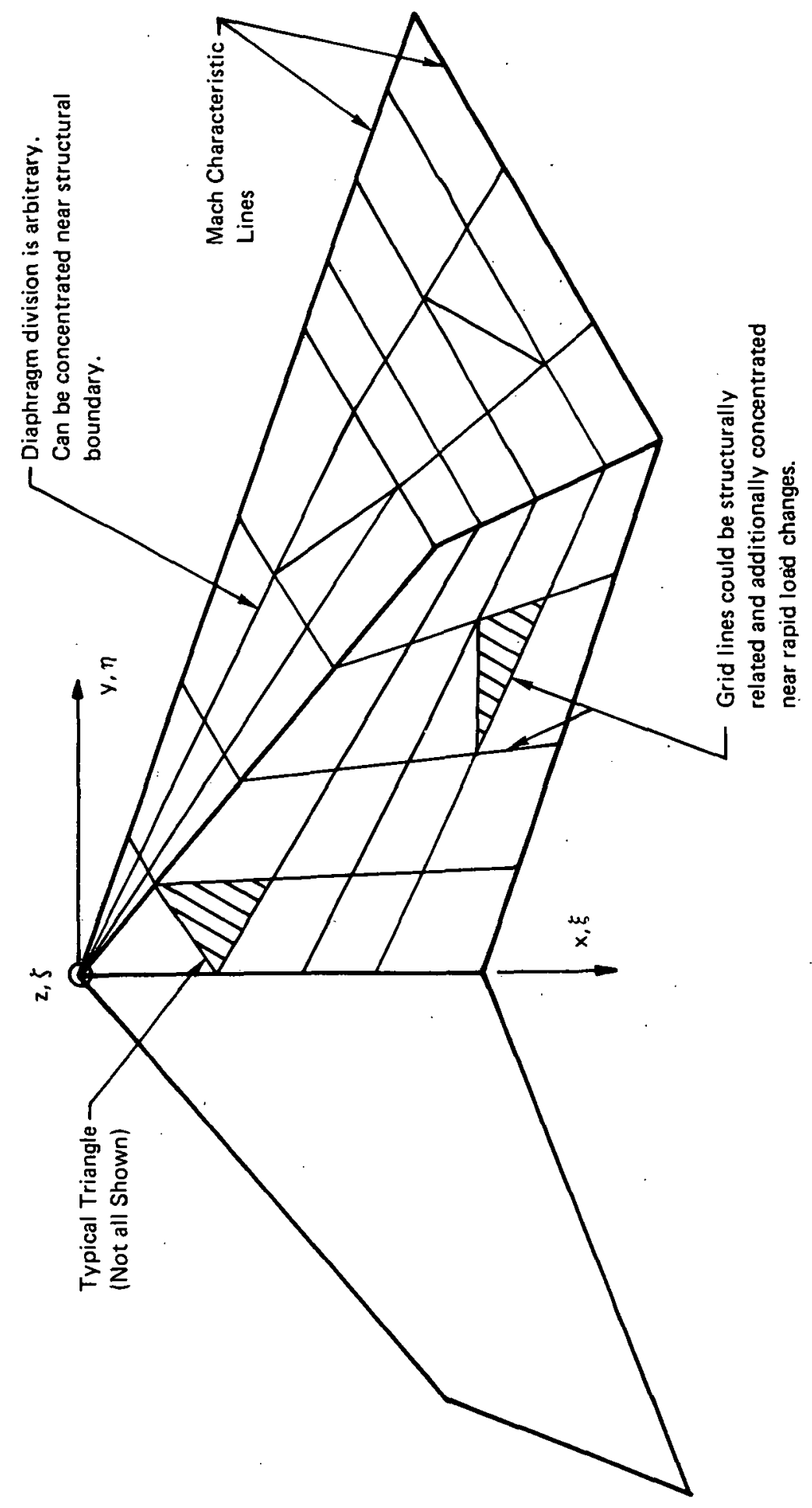

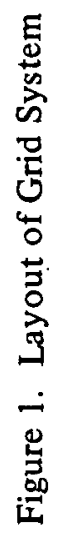


is the velocity potential influence coefficient matrix for the ith element nodes due to the source distribution in the jth element. Numerical integration of $\Phi_{\mathrm{ij}}$ is described in the Appendix. Then considering all the elements, the velocity potential for the system can be written as

$$
\phi=-\mathrm{U} \ell[\Phi]\{\sigma\}
$$

where $\phi$ is a column vector of nodal velocity potentials and $\Phi$ is the total velocity potential influence coefficient matrix.

\section{Boundary Conditions}

The source strength nodal vector $\sigma$ in Eq. (12) must be such that the following boundary conditions are satisfied:

- the kinematic boundary condition on the lifting surface given by

$$
\frac{\partial \varphi}{\partial \vec{n}} \mathrm{e}^{\lambda \mathrm{t}}=\ell \frac{\mathrm{D} \overline{\mathrm{Z}}}{\mathrm{Dt}}
$$

where

and

$\frac{\partial \varphi}{\partial \vec{n}}$ is the derivative of the velocity potential normal to the surface at the field point $X$,

$$
\frac{\mathrm{D}}{\mathrm{Dt}}=\frac{\partial}{\partial \mathrm{t}}+\frac{\mathrm{U}}{\ell} \frac{\partial}{\partial \mathrm{x}}
$$

is the material derivative in the streamwise direction.

- in the case of a subsonic leading edge, the velocity potential difference in the diaphragm

$$
\Delta \phi_{\mathrm{d}}=\left(\phi_{\text {upper }}-\phi_{\text {lower }}\right)_{\mathrm{d}} \text { must be zero }
$$

- the pressure difference in the wake

$$
\Delta \mathrm{p}_{\mathrm{s}}=\left(\mathrm{p}_{\text {upper }}-\mathrm{p}_{\text {lower }}\right)_{\mathrm{s}} \text { must be zero. }
$$

The boundary conditions for interfering wings require special considerations described later.

Subsonic Leading Edge Case

Antisymmetry of the nodal source distribution $\sigma$ and of $\phi$ with respect to the plane of the wing in the lifting case implies that Equations (12) and (13) may be used to relate potential and source strength jumps in partitioned matrix notation as

$$
\left\{\frac{\Delta \phi_{\mathrm{w}}}{\Delta \phi_{\mathrm{d}}}\right\}=-\mathrm{U} \ell\left[\frac{\Phi_{\mathrm{ww}}}{\Phi_{\mathrm{dw}}} \frac{\Phi_{\mathrm{wd}}}{\Phi_{\mathrm{dd}}}\right]\left\{\frac{\Delta \sigma_{\mathrm{w}}}{\Delta \sigma_{\mathrm{d}}}\right\}
$$


where the subscripts ' $w$ ' and ' $d$ ' denote the nodes situated on the wing and diaphragm respectively.

Since in the diaphragm $\Delta \phi_{\mathrm{d}}=0$ (Ref. 18), the source strength vector $\Delta \sigma_{\mathrm{d}}$ from the second of Equation (17) is

$$
\left\{\Delta \sigma_{\mathrm{d}}\right\}=-\Gamma\left\{\Delta \sigma_{\mathrm{w}}\right\}
$$

where

$$
\Gamma=\Phi_{\mathrm{dd}}^{-1} \Phi_{\mathrm{dw}}
$$

Using this solution in the first set of matrix Equation (17), the velocity potential distribution on the lifting surface is given by

$$
\Delta \phi_{\mathrm{W}}=-\mathrm{Ul} \widetilde{\Phi}_{\mathrm{wW}} \Delta \sigma_{\mathrm{W}}
$$

in which

$$
\widetilde{\Phi}_{w w}=\Phi_{w w}-\Phi_{w d} \Gamma
$$

\section{Kinematic Boundary Conditions}

The Isolated Wing Case

$\ell \frac{\mathrm{D} \overline{\mathrm{Z}}}{\mathrm{Dt}}=\mathrm{w} \mathrm{e}^{\lambda \mathrm{t}}$. Let $\rho_{\mathrm{j}}$ denote a column vector of nodal kinematic deformation modes of an element $\mathrm{j}$ in the fore Mach cone region. Then the interpolated deformation within the element $\mathrm{j}$ can be expressed in terms of the element nodal values as

$$
\overline{\mathrm{Z}}\left(\xi_{\mathrm{j}}, \eta_{\mathrm{j}}, \mathrm{t}\right)=\Omega(\xi, \eta) \rho_{\mathrm{j}} \mathrm{e}^{\lambda \mathrm{t}}
$$

If the mean position of the lifting surface is parallel to the $x-y$ plane, the downwash from Eq. (13) is

$$
\frac{1}{\ell} \frac{\partial \varphi}{\partial \zeta} \mathrm{e}^{\lambda \mathrm{t}}=\mathrm{w} \mathrm{e}^{\lambda \mathrm{t}}=\ell\left(\frac{\partial}{\partial \mathrm{t}}+\frac{\mathrm{U}}{\ell} \frac{\partial}{\partial \xi}\right) \overline{\mathrm{Z}}
$$

or in nondimensional form using Equation (22)

$$
\frac{w\left(\xi_{j}, \eta_{j}\right)}{U}=\left(\bar{\lambda} \Omega+\Omega_{\xi}\right) \rho_{j}
$$

in which $\bar{\lambda}=\left(\frac{\alpha \ell}{U}+\frac{i \omega \ell}{U}\right)$ is the complex reduced frequency, and

$$
\Omega_{\xi}=\frac{\partial \Omega}{\partial \xi} \text {. }
$$

Thus for the isolated case, the source strength distribution $\sigma \mathrm{e}^{\lambda t}$ in Equation (4) will be replaced by

$$
\sigma\left(\Xi_{j}\right)=\left(\bar{\lambda} \Omega+\Omega_{\xi}\right) \rho_{j}
$$


Utilizing the relation between element nodal displacements $\boldsymbol{\rho}_{\mathrm{j}}$ and system displacements $\mathrm{q}$ as given by the Boolean matrix $\mathbf{a}_{\mathbf{j}}$

$$
\rho_{j}=a_{j} q
$$

the system velocity potential analogous to Eq. (12) may be expressed in matrix form as

$$
\Delta \phi=-2 U \ell[\Phi] \mathrm{q}
$$

\section{Interfering Nearly Parallel Wings}

The determination of source strengths in the case of interfering planes is more complex than in the isolated case. Ashley in Reference 9 has discussed in detail some practical assumptions for relating the source strength distribution to the kinematic boundary conditions. In the present analysis the following assumptions based on Reference 9 are made:

(i) convenient diaphragms can be established between the lifting surfaces and the Mach hyperbolae

(ii) induced normal wash at one diaphragm due to the presence of the second lifting surface can be disregarded.

Considering two planar interfering wings (Figure 2 ), the source distribution $\sigma_{1 \mathrm{w}}^{\mathrm{L}}$ on the lower surface of wing 1 and $\sigma_{2 w}$ on the upper surface of wing 2 are unaffected by the interference. Then these source strengths using Eq. 23 can be expressed as

$$
\sigma_{1 \mathrm{w}}^{\mathrm{L}}=-\frac{\ell}{\mathrm{U}} \frac{\mathrm{D} \overline{\mathrm{Z}}_{1}}{\mathrm{Dt}}
$$

and

$$
\sigma_{2 \mathrm{w}}^{\mathrm{U}}=\frac{\ell}{\mathrm{U}} \frac{\mathrm{D} \overline{\mathrm{Z}}_{2}}{\mathrm{Dt}}
$$

The source strength distributions on the upper surface of wing 1 and the lower surface of wing 2, because of interference, are modified by the induced downwash in their respective planes. The induced downwash on the upper surface of wing 1 due to source distributions on the lower surface of wing 2 and its diaphragm may be written as

$$
w_{12}=w_{12 w} \sigma_{2 w}^{L}+w_{12 d} \sigma_{2 d}^{L}
$$

where

\footnotetext{
$\mathbf{w}_{12}$ is a nodal column vector of induced downwash on wing 1 and its diaphragm

$W_{12}$ is the velocity influence coefficient matrix for the wing 1 due to interference of source distributions on the lower surface of wing 2 and its diaphragm.
} 


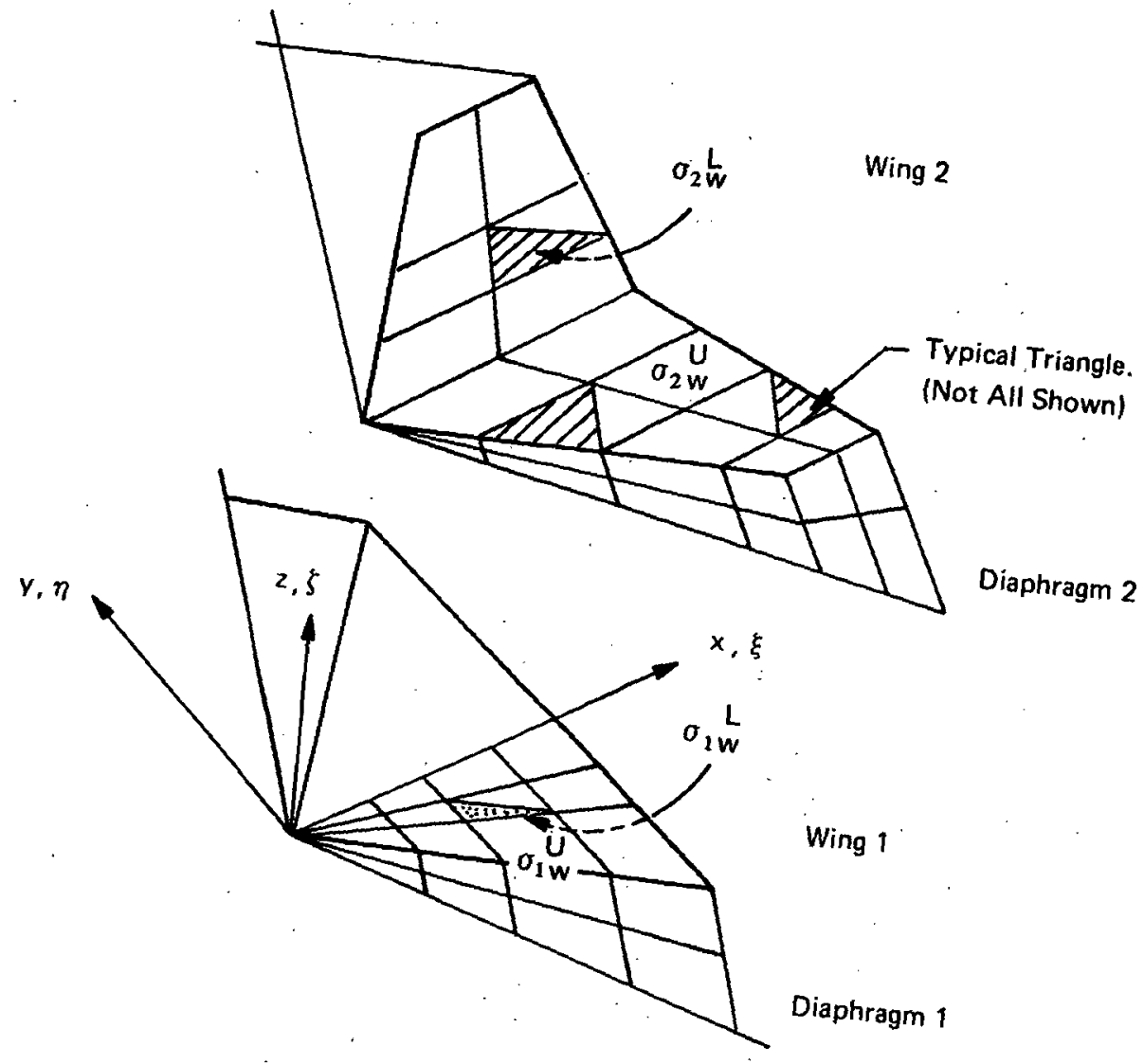

Figure 2. Layout of Grid System -2 Wings 
The subscripts $w$ and denote control points on the wing and its associated diaphragms, and the superscripts $U$ and $L$ denote upper and lower surfaces, respectively. Derivation and numerical integration of the downwash influence coefficient matrix $W_{\mathrm{ij}}$ for the triangular element is described in the Appendix (see Eqs. A13-A20).

In the following work, in accord with assumption (ii), the effect of induced downwash $\mathbf{w}_{12}$ in the diaphragm has been disregarded. Since the wing planes are assumed to be nearly parallel, the side wash contribution to the computation of $w_{12}$ has also been neglected. Then the source strength required to satisfy the total normal velocity condition on the upper surface of wing 1 is given by

$$
\sigma_{1 \mathrm{w}}^{\mathrm{U}}=\frac{\ell}{\mathrm{U}} \frac{\mathrm{D \widetilde {Z } _ { 1 }}}{\mathrm{Dt}} \cdot \mathrm{w}_{12 \mathrm{w}} \underset{2 \mathrm{w}}{\mathrm{L}}-\mathrm{w}_{12 \mathrm{~d}} \sigma_{2 \mathrm{~d}}^{\mathrm{L}}
$$

Similarly the required source strength distribution on the lower surface of wing 2 is given by

$$
\sigma_{2 w}^{L}=-\left[\frac{\ell}{U} \frac{D \widetilde{Z}_{2}}{D t}-W_{21 w} \sigma \underset{1 w}{U}-W_{21 d} \sigma_{1 d}^{U}\right]
$$

Eqs. (32) and (33) can be rearranged as

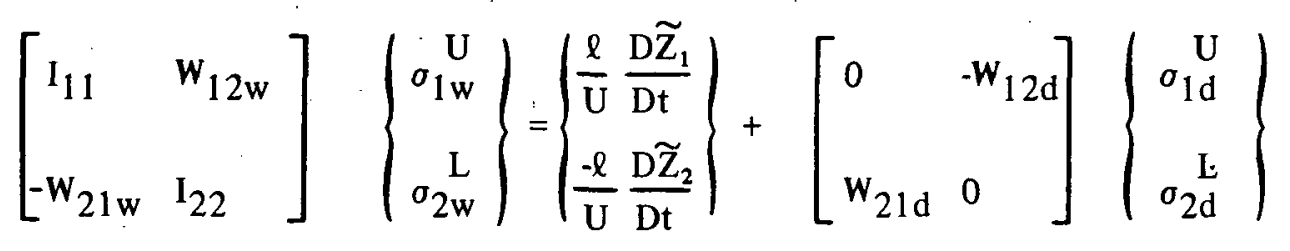

The relation between the source strengths in the diaphragm and wing is given by Equation (18). Rewriting this equation as

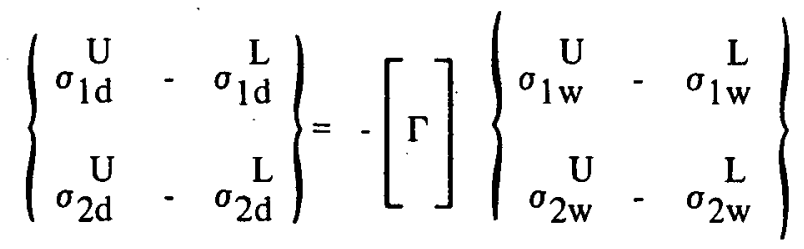

and using the condition of downwash continuity in the diaphragm, i.e.,

$$
\sigma_{d}^{U}=-\sigma_{d} L
$$

the required source strength in the diaphragm may be written as

$$
\left\{\begin{array}{c}
\sigma_{1 \mathrm{~d}}^{\mathrm{U}} \\
\mathrm{L} \\
\sigma_{2 \mathrm{~d}}
\end{array}\right\}=[\widetilde{\Gamma}]\left(\begin{array}{r}
\sigma_{1 \mathrm{w}} \\
\mathrm{L} \\
\sigma_{2 \mathrm{w}}
\end{array}\right\}-[\widetilde{\Gamma}]\left\{\begin{array}{c}
\mathrm{L} \\
\sigma_{1 \mathrm{w}} \\
\mathrm{U} \\
\sigma_{2 \mathrm{w}}
\end{array}\right)
$$


where

$$
\widetilde{\Gamma}=\frac{1}{2}\left[\begin{array}{cc}
-I & 0 \\
0 & I
\end{array}\right][\Gamma]\left[\begin{array}{ll}
I & 0 \\
0 & -I
\end{array}\right]
$$

Eqs. (29) and (30) then give

$$
\left\{\begin{array}{r}
\mathrm{U} \\
\sigma_{1 \mathrm{~d}} \\
\sigma_{2 \mathrm{~d}}^{\mathrm{L}}
\end{array}\right\}=[\widetilde{\Gamma}]\left\{\begin{array}{r}
\mathrm{U} \\
\sigma_{1 \mathrm{w}} \\
\mathrm{L} \\
\sigma_{2 \mathrm{w}}
\end{array}\right\}+[\widetilde{\Gamma}]\left\{\begin{array}{ll}
\frac{\ell}{\mathrm{U}} & \frac{\mathrm{D} \widetilde{Z}_{1}}{\mathrm{Dt}} \\
\frac{\ell}{\mathrm{U}} & \frac{\mathrm{D} \widetilde{Z}_{2}}{\mathrm{Dt}}
\end{array}\right\}
$$

Substituting for $\sigma_{1 \mathrm{~d}}^{\mathrm{U}}$ and $\sigma_{2 \mathrm{~d}}^{\mathrm{L}}$ in Eq. (34), the following matrix equation is obtained:

$$
\begin{aligned}
& {\left[\begin{array}{ll}
\mathrm{I}_{11} & \mathrm{~W}_{12 \mathrm{w}} \\
-\mathrm{W}_{21 \mathrm{w}} & \mathrm{I}_{22}
\end{array}\right]-\left[\begin{array}{ll}
0 & -\mathrm{W}_{12 \mathrm{~d}} \\
\mathrm{~W}_{21 \mathrm{~d}} & 0
\end{array}\right][\widetilde{\Gamma}]\left\{\begin{array}{c}
\sigma_{1 \mathrm{w}} \\
\mathrm{L} \\
\sigma_{2 \mathrm{w}}
\end{array}\right\}=\left\{\begin{array}{cc}
\frac{\ell}{\mathrm{U}} & \frac{\mathrm{D} \widetilde{Z}_{1}}{\mathrm{Dt}} \\
\frac{-\ell}{\mathrm{U}} & \frac{\mathrm{D} \widetilde{Z}_{2}}{\mathrm{Dt}}
\end{array}\right\}}
\end{aligned}
$$

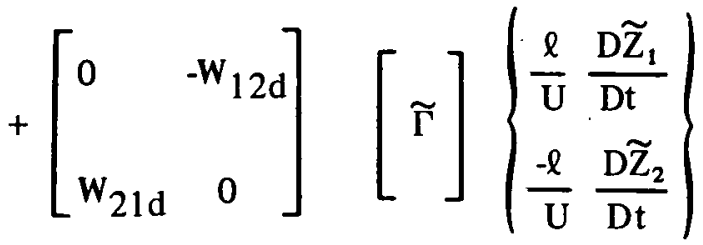

The input downwash terms $\frac{\ell}{U} \frac{D \widetilde{Z}_{i}}{D t}$ are calculated for the system structural displacements $q$ at each grid point, and the slopes $\frac{\partial q}{\partial x}$, by

$$
\frac{\ell}{U} \frac{D \widetilde{Z}_{i}}{D t}=\lambda\{q\}+\left\{\frac{\partial q}{\partial x}\right\}
$$

Using Eq. (41) in Eqs. (29), (30) and (40), the difference in the source distribution across the wing surfaces can be written as

$$
\left\{\Delta \sigma_{\mathrm{w}}\right\}=[\Psi]\{\mathrm{q}\}
$$

where $\Psi$ is a transformation matrix relating source strength and displacement vectors. The velocity potential differences across the wing surfaces are then obtained by substitution of Eq. (42) into Eq. (20).

\section{Concerning Subsonic Trailing Edges}

In this case the source strength distribution in the wake can be determined from the pressure continuity condition across the wake sheet and the trailing edge potentials. It may then be expressed in terms of the distribution on the wing and diaphragm and condensation of velocity potential in the wake performed similar to Equation (21). 
For interfering cases, induced downwash matrices can similarly be modified. However, the subsonic trailing edge case has not been included in the present analyses and programs.

\section{Consistent Nodal Forces}

The velocity potential within the $\mathrm{i}^{\text {th }}$ element can be expressed in terms of nodal values $\Delta \phi_{\mathrm{i}}$ and the interpolation matrix $\Omega$ as

$$
\Delta \varphi\left(\mathrm{X}_{\mathrm{i}}\right)=[\Omega]\left\{\Delta \phi_{\mathrm{i}}\right\} \mathrm{e}^{\lambda \mathrm{t}}
$$
is given by

Since the pressure distribution within the $\mathrm{i}^{\text {th }}$ element from the linearized Bernoulli's equation

$$
p\left(X_{i}\right) e^{\lambda t}=\rho\left[\frac{\partial}{\partial t}+\frac{U}{\ell} \frac{\partial}{\partial x}\right] \Delta \varphi\left(X_{i}\right)
$$

from Equations (43), (23), (24), the pressure distribution is

$$
\mathrm{p}\left(\mathrm{X}_{\mathrm{i}}\right)=+\frac{\rho \mathrm{U}}{\ell}\left[\bar{\lambda} \Omega+\Omega_{\mathrm{x}}\right] \Delta \phi_{\mathrm{i}}
$$

The virtual work done on the $\mathrm{i}^{\text {th }}$ element by the pressure through virtual displacement $\ell \delta \mathrm{Z}\left(\mathrm{X}_{\mathrm{j}}\right)$ using Eq. (22) is

$$
\delta \widetilde{\mathrm{W}}_{\mathrm{ji}}=\rho \mathrm{U} \ell^{2} \cdot \delta \rho_{\mathrm{j}}^{\mathrm{t}} \iint_{\mathrm{S}_{\mathrm{i}}}\left[\bar{\lambda} \Omega^{\mathrm{t}} \Omega+\Omega^{\mathrm{t}} \Omega_{\mathrm{x}}\right] \mathrm{dx} \mathrm{dy} \Delta \phi_{\mathrm{i}}
$$

Summing over all elements on the lifting surface and using Eq. (28), the virtual work principle yields the nodal forces,

$$
\begin{aligned}
\mathbf{p} & =\rho \mathrm{U} \ell[\bar{\lambda} \mathbf{A}+\mathbf{B}] \Delta \phi \\
& =-2 \rho \mathrm{U}^{2} \ell^{2}[\bar{\lambda} \mathbf{A}+\mathbf{B}][\Phi] \mathbf{q}
\end{aligned}
$$

where $A$ and $B$, real pressure matrices, are assemblies of element matrices defined by

$$
\begin{aligned}
& A=\underset{n}{\Sigma} a_{n}^{t} A_{n} a_{n} \\
& B=\underset{n}{\sum} a_{n}^{\mathfrak{t}} B_{n} a_{n}
\end{aligned}
$$

The element matrices are given by

$$
A_{j}=\iint_{S_{j}} \Omega^{t} \Omega d S
$$




$$
B_{j}=\iint_{S_{j}} \Omega^{t} \Omega_{x} d S
$$

and ' $n$ ' represents summation over wing elements only.

\section{Generalized Forces}

If $q_{\ell}$ and $q_{m}$ denote two nondimensional nodal deformation modes, the virtual work done in a virtual displacement $\delta q_{\ell}$ is, using Eq. (47)

$$
\begin{aligned}
\delta \tilde{W}_{\ell \mathrm{m}} & =\ell \delta_{\mathrm{q}_{\ell}}{ }^{\mathrm{t}} \mathrm{p}_{\mathrm{m}} \\
& =-2 \rho U^{2} \dot{\ell}^{3} \delta \mathrm{q}_{\ell}{ }^{\mathrm{t}}[\bar{\lambda} \mathrm{A}+\mathrm{B}][\Phi] \mathbf{q}_{\mathrm{m}} \\
& =-2 \rho U^{2} \ell^{3} \delta_{\mathrm{q}_{\ell}}{ }^{\mathrm{t}} \widetilde{\mathrm{Q}}_{\ell \mathrm{m}} \mathrm{q}_{\mathrm{m}} \quad \text { say. }
\end{aligned}
$$

The matrix of dimensionless generalized force coefficients is then defined by

$$
-\frac{1}{2 \rho U^{2} \ell^{3}} \frac{\partial}{\partial q_{\ell}}\left(\frac{\partial \tilde{W}_{l m}}{\partial q_{m}}\right)=\widetilde{Q}_{\ell m} \text {, }
$$

the elements of $\widetilde{Q}$. 


\section{FLUTTER ANALYSIS}

The flutter equations of motion for a flight structure may be written

$$
K q+M \ddot{q}+4 q_{o} \ell A\left(k, M_{o}\right) q=0
$$

where $\mathrm{K}, \mathrm{M}, \mathrm{A}$ are ( $\mathrm{nxn}$ ) stiffness, inertia and aerodynamic matrices respectively,

q is a ( $\mathrm{nxl})$ displacement vector

$\ell \quad$ is a reference length

$\mathrm{q}_{\mathrm{o}}=\frac{\rho \mathrm{U}^{2}}{2}=\frac{\rho \mathrm{a}_{0}^{2} \mathrm{M}_{0}^{2}}{2}$ is the dynamic pressure and

$\mathrm{k}=\frac{\omega \ell}{\mathrm{U}}$ is the reduced frequency

$\rho \quad$ is the air density

$\mathrm{U} \quad$ is the true flight speed.

For small oscillations, the deformation of the structure can be approximated by a linear combination of a few of the lower frequency natural modes as

$$
\mathbf{q}=\chi \bar{\eta}
$$

where $\chi$ is a nxN modal matrix, $(\mathrm{N}<<\mathrm{n})$ and $\bar{\eta}$ is a vector of generalized coordinates. Taking the motion to be of the form

$$
\bar{\eta}=\eta \mathrm{e}^{\lambda \mathrm{t}}
$$

Eqn (54) becomes, for zero damping at the flutter boundary $(\alpha=0)$,

$$
\mathrm{K}_{\mathrm{ii}} \eta_{\mathrm{i}}-\omega^{2} \mathrm{M}_{\mathrm{ii}} \eta_{\mathrm{i}}+4 \mathrm{q}_{\mathrm{o}} \ell \sum_{\mathrm{j}} \mathrm{Q}_{\mathrm{ij}}\left(\mathrm{k}, \mathrm{M}_{\mathrm{o}}\right) \eta_{\mathrm{j}}=0
$$

for $\mathrm{i}=1 \ldots \mathrm{N}$, where $\mathrm{K}_{\mathrm{ii}}, \mathrm{M}_{\mathrm{ii}}$ and $\mathrm{Q}_{\mathrm{ij}}$ are the generalized stiffness, inertia and aerodynamic matrix coefficients respectively.

Using a reference frequency $\omega_{R}$ and a reference dynamic pressure $\dot{q}_{0}^{*}=\frac{\rho_{0}^{*} a_{0}^{* 2} M_{O}^{2}}{2}$, where * parameters refer to sea level condition, say, Eqn (57) can be rewritten in nondimensional form as

$$
\left[\left[\left(\frac{\omega_{\mathrm{i}}}{\omega_{\mathrm{R}}}\right)^{2}\right]+\delta\left(\frac{4 \mathrm{q}_{\mathrm{o}}^{*} \mathrm{l}}{\omega_{\mathrm{R}}^{2}}\right)\left[\mathbf{M}_{\mathrm{ii}}\right]^{-1}\left[\mathrm{Q}\left(\mathrm{k}, \mathrm{M}_{\mathrm{o}}\right)\right]\right] \eta=\left(\frac{\omega}{\omega_{\mathrm{R}}}\right)^{2} \eta
$$

in which $\delta=\frac{\mathrm{q}_{\mathrm{o}}}{\mathrm{q}_{\delta}^{*}}$ is a dynamic pressure ratio, the $\omega_{\mathrm{i}}$ are the natural frequencies of the $\mathrm{K}-\mathrm{M}$ system 
and $\omega, \eta$ are the eigenvalue and eigenvector of the system respectively. Since the evaluation of $\mathbf{Q}$ requires a priori knowledge of the flutter frequency, the eigenvalue problem cannot be solved directly. Several iteration schemes have appeared in the literature, the method for the determination of flutter eigensolutions employed in this work being as follows:

.For a given Mach number, compute $Q\left(k, M_{0}\right)$ for a range of reduced frequencies, $k$. Since the elements $Q_{i j}$ vary smoothly with $k$, each $Q_{i j}$ can be approximated by a power series/spline fit over a chosen range of $k$, as

$$
\mathbf{Q}_{\mathrm{ij}}(\mathrm{k})=\sum_{\mathrm{n}=\mathrm{o}}^{\overline{\mathrm{N}}} \cdot \widetilde{\mathbf{Q}}_{\mathrm{ij}}, \mathrm{n} \cdot \mathrm{k}^{\mathrm{n}}
$$

For a given Mach Number, the variables in Eqn. (58) are the density $\rho$ and the speed of sound $\mathrm{a}_{\mathrm{o}}$. Generally, the relation between $\rho$ and $a_{0}$ is given in the form of standard atmospheric tables or tunnel operating characteristics, effectively reducing the unknowns to one variable, say $\rho$. Rewrite the definitions of dynamic pressure and reduced frequency in terms of Mach number as

$$
\mathrm{q}_{\mathrm{o}}=\frac{1}{2} \rho \mathrm{U}^{2}=\frac{1}{2} \rho \mathrm{M}_{\mathrm{o}}{ }^{2} \mathrm{a}_{\mathrm{o}}{ }^{2}=\frac{\rho_{\mathrm{O}}^{*} \mathrm{a}_{\mathrm{o}}^{* 2} \mathrm{M}_{\mathrm{o}}{ }^{2}}{2} \cdot \delta
$$

and

$$
\mathrm{k}=\frac{\dot{\omega} \ell}{\mathrm{U}}=\frac{\omega \ell}{\mathrm{M}_{\mathrm{o}} \mathrm{a}_{\mathrm{o}}}
$$

The iterative flutter solution in the atmospheric flight condition begins with the assumption of a low density $\rho$ and the corresponding speed of sound $a_{n}$. Assuming some starting value of $\omega=$ $\omega_{\mathrm{R}}, \mathrm{k}$ and $\delta$ are then determinable. For this $\mathrm{k}, \mathrm{Q}_{\mathrm{ij}}$ 's are interpolated. With these quantities all the eigenvalues of Eqn. (58) are determined. Since $Q$ is complex, the eigenvalues are generally complex, with their imaginary parts positive for decaying motion, which is inconsistent with the harmonic motion assumed. In order to determine consistent results, density is now increased and the above process repeated until one or more of the imaginary parts of $\omega$ change sign from positive to negative. The reduced frequency ' $k$ ' is then recomputed using the smallest real part of $\omega$ which has a negative imaginary part. The density $\rho$ is then interpolated between those values of $\rho$ which yield positive and negative imaginary parts of $\omega$ to obtain acceptable convergence to zero of the imaginary part of ' $\omega$ '. In practice rapid convergence to a real reduced frequency is obtained since the flutter formulation given by Eqn. (58) is generally not sensitive to small changes in $\mathrm{k}$. In most cases linearly interpolated values of $\rho$ are adequate for determination of the critical value. The critical dynamic pressure $q_{o c r}$, critical flight speed $U_{c r}$, and the flutter frequency $\omega_{\mathrm{f}}$ are finally determined. A typical flow chart is presented in Figure 13.

Presentation of the flutter boundary in the current examples is in terms of the conventional stiffness-altitude parameter, $\frac{\mathrm{V}}{\omega_{\mathrm{R}} \ell} \cdot \frac{1}{\sqrt{\mu}}$ where $\mu$, the ratio of structural mass to air mass is chosen by
the user. 


\section{RESULTS AND DISCUSSION}

The numerical results presented in this section have been obtained from two independent programs developed for isolated and interfering cases.

The characteristics of and parameters related to the various results are summarized in Table 1.

Isolated Wings

\section{Aerodynamics for Isolated Wings}

The accuracy of any unsteady aerodynamic method is critically illustrated by comparison of velocity potentials. Figures 3 to 5 compare the velocity potential distribution for a cropped delta wing with a low subsonic-leading edge at $\mathrm{M}_{\mathrm{O}}=1.054$ for steady and oscillatory cases. Five consistent triangular elements compare very well with 30-box results from Reference 12. For the same cropped delta wing, generalized aerodynamic coefficients are presented for heave and pitch about a mid-chord axis at Mach numbers 1.118 and 1.201, in Table 2 and Figure 6. For such low Mach numbers and so few elements, the generalized coefficients deduced from the present method are in encouragingly good agreement with Reference 12 with the exception of moments due to pitching.

Table 3 shows the generalized coefficients for a rectangular wing of aspect ratio 2.0 at $M_{O}=$ 2.0 in heave and pitch motion with $k=0.3$, and in steady flow at $\mathbf{M}_{\mathbf{0}}=1.2$. These have been compared with References 19 and 11 , respectively. Vector plots of generalized forces are presented in Figure 7 and show generally good agreement.

The next example considers an AGARD swept wing of aspect ratio 1.45. The wing motions considered are heave, pitching about center chord, quadratic bending in the chordwise direction and quadratic bending in the spanwise direction, at two Mach numbers and two frequencies in each case. Comparisons have been made with Reference 20 which uses 30 to 40 characteristic boxes and Reference 19 which uses 17 chord wise Mach boxes whereas the present method uses only six triangles. Table 4 shows the generalized coefficients for $\mathrm{M}_{\mathrm{O}}=1.2, \mathrm{k}=0.5$. For the first three modes good agreement has been obtained with References 20 and 19 while the fourth mode compares well with Reference 20 only. It appears that the Mach box results in Reference 19 are wrong or inaccurate for this mode. Table 5 shows $\mathrm{Q}_{\mathrm{ij}}$ 's at $\mathrm{M}_{\mathrm{o}}=1.2, \mathrm{k}=1.0$ for the same modes. Once again good agreement with Reference 20 is obtained.

Tables 6 and 7 show generalized coefficients at $M_{0}=2.0$ for $k=0.5$ and $k=1.4$ respectively. Comparisons have been made again with References 19 and 20 in the former and with Reference 19 in the latter case. Results in Table 6 are in good agreement with Reference 20 but for the fourth mode (spanwise bending), again Reference 19 agrees with neither.

\section{Flutter Solutions for Isolated Wings (NASA “HT-7” Example)}

The basic purpose in the development of consistent aerodynamic forces is ultimately to improve the accuracy of aeroelastic solutions. Generalized forces have been used to determine the flutter boundary for a wing of aspect ratio 2.50 and taper ratio 0.3 , known at NASA Langley as the HT-7 configuration. The leading edge sweepback angle is $50.5^{\circ}$. Mode shapes, generalized masses and natural frequencies are given in Reference 21. Flutter boundaries at $M_{0}=1.3,1.573$ and 1.64 were determined using the flutter equation (58). The altitude stiffness ratio $\frac{b_{0} \omega_{2} \sqrt{\mu}}{a_{0}}$ and the flutter 


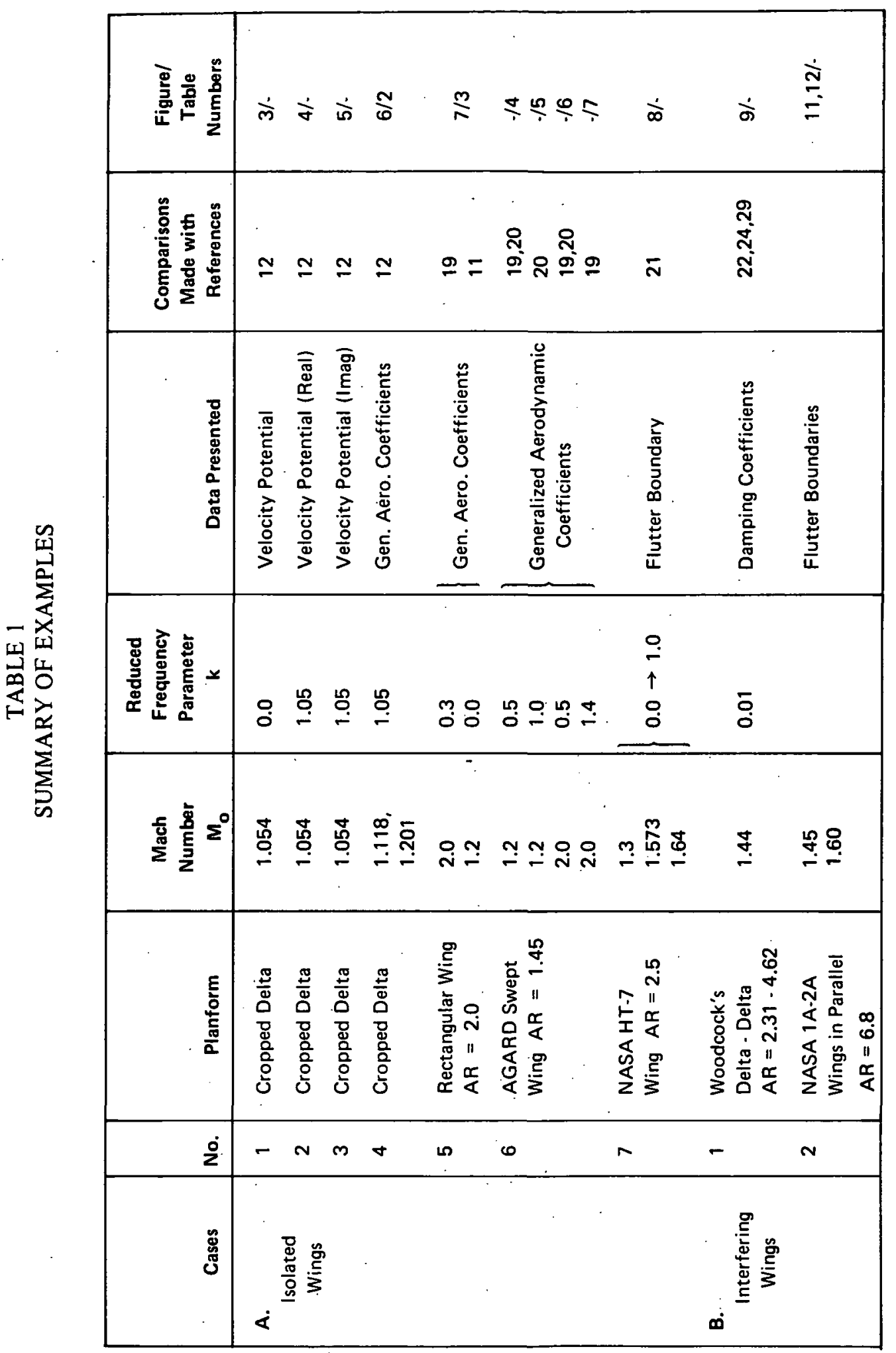


TABLE 2

COMPARISON OF AERODYNAMIC GENERALIZED COEFFICIENTS $Q_{i j}$ FOR A CROPPED DELTA WING

$\mathrm{M}_{\mathrm{O}}=1.118,1.201, \mathrm{k}=1.05(\widetilde{\omega}=0.3)$

Modes: $\mathrm{q}_{1}=2 / 7, \mathrm{q}_{2}=\mathrm{x}-\mathrm{x}_{\text {mid }}$ chord

\begin{tabular}{|c|c|c|c|c|c|}
\hline \multicolumn{2}{|c|}{ Method } & \multicolumn{2}{|c|}{ Ref. 12} & \multicolumn{2}{|c|}{ Present } \\
\hline \multicolumn{2}{|c|}{$\begin{array}{l}\text { Nò. of } Q \\
\text { Elements }\end{array}$} & \multicolumn{2}{|c|}{30} & \multicolumn{2}{|c|}{6} \\
\hline$m_{0}$ & $Q_{i j}$ & Real & Imaginary & Real & Imaginary \\
\hline \multirow{4}{*}{1.118} & $\overline{a_{11}}$ & 0.0602 & 0.3163 & 0.0519 & 0.2849 \\
\hline & $Q_{12}$ & 1.1603 & -0.0915 & 1.0811 & -0.0452 \\
\hline & $\mathrm{O}_{21}$ & -0.0504 & -0.0746 & -0.0353 & -0.0390 \\
\hline & $\mathrm{O}_{22}$ & -0.1631 & 0.3923 & -0.0578 & 0.3039 \\
\hline \multirow{4}{*}{1.201} & $a_{11}$ & 0.0646 & 0.2992 & 0.0560 & 0.2763 \\
\hline & $\mathrm{O}_{12}$ & 1.0727 & -0.1159 & 1.0134 & -0.0678 \\
\hline & $\mathrm{O}_{21}$ & -0.0437 & -0.0738 & -0.0359 & -0.0497 \\
\hline & $\mathrm{O}_{22}$ & -0.1574 & 0.3684 & -0.0847 & 0.3132 \\
\hline
\end{tabular}


TABLE 3

COMPARISON OF AERODYNAMIC GENERALIZED COEFFICIENTS $Q_{i j}$ FOR RECTANGULAR WING OF ASPECT RATIO 2

$\mathrm{M}_{\mathrm{o}}=2.0, \mathrm{k}=0.3$ and $\mathrm{M}_{\mathrm{O}}=1.2, \mathrm{k}=0$

Modes: $\mathrm{q}_{1}=1.0, \mathrm{q}_{2}=(\mathrm{x}-\mathrm{c} / 2)$

\begin{tabular}{|c|c|c|c|c|c|c|}
\hline \multicolumn{2}{|c|}{ Method } & \multicolumn{2}{|c|}{ Mach Box } & Ref. 19 & \multicolumn{2}{|c|}{ Present } \\
\hline \multicolumn{2}{|c|}{$\begin{array}{l}\text { No, of } \mathcal{G} \\
\text { Elements }\end{array}$} & \multicolumn{3}{|c|}{20} & \multicolumn{2}{|c|}{4} \\
\hline$M_{0}$ & k & $a_{i j}$ & Real & Imaginary & Real & Imaginary \\
\hline 2.0 & 0.3 & $\begin{array}{l}Q_{11} \\
Q_{12} \\
Q_{21} \\
Q_{22}\end{array}$ & $\begin{array}{c}-0.191 \\
-21.87 \\
-0.116 \\
-10.30\end{array}$ & $\begin{array}{l}-6.536 \\
-2.852 \\
-3.072 \\
-1.929\end{array}$ & $\begin{array}{c}-0.217 \\
-22.07 \\
-0.145 \\
-10.65\end{array}$ & $\begin{array}{r}-6.55 \\
2.56 \\
-3.18 \\
-1.75\end{array}$ \\
\hline \multicolumn{2}{|c|}{ Method } & \multicolumn{2}{|c|}{ Mach Box } & Ref. 11 & \multicolumn{2}{|c|}{ Present } \\
\hline \multicolumn{2}{|c|}{$\begin{array}{l}\text { No. of } q \\
\text { Elements }\end{array}$} & \multicolumn{3}{|c|}{20} & \multicolumn{2}{|c|}{4} \\
\hline $\mathbf{M}_{\mathbf{O}}$ & k & $o_{i j}$ & Real & Imaginary & Real & Imaginary \\
\hline 1.2 & 0.0 & $\begin{array}{l}\mathrm{O}_{12} \\
\mathrm{O}_{22}\end{array}$ & $\begin{array}{c}3.836 \\
-0.3783\end{array}$ & & $\begin{array}{r}3.900 \\
-0.345\end{array}$ & \\
\hline
\end{tabular}


TABLE 4

COMPARISON OF AERODYNAMIC GENERALIZED COEFFICIENTS

$\mathrm{M}_{\mathrm{o}}=1.2, \mathrm{k}=0.5$

$Q_{i j}$ FOR AGARD SWEPT WING OF ASPECT RATIO 1.45

Modes: $\mathrm{q}_{1}=1.0, \mathrm{q}_{2}=\left(\mathrm{x}-\mathrm{c}_{\mathrm{r}} / 2\right), \mathrm{q}_{3}=\left(\mathrm{x}-\mathrm{c}_{\mathrm{r}} / 2\right)^{2}, \mathrm{q}_{4}=\mathrm{y}^{2}$

\begin{tabular}{|c|c|c|c|c|c|c|}
\hline Method & \multicolumn{2}{|c|}{ Present } & \multicolumn{2}{|c|}{ Mach Box Ref. 19} & \multicolumn{2}{|c|}{ Char. Box Ref. 20} \\
\hline $\begin{array}{l}\text { No. of } \boldsymbol{E} \\
\text { Elements }\end{array}$ & \multicolumn{2}{|c|}{6} & \multicolumn{2}{|c|}{17} & \multicolumn{2}{|c|}{$30+$} \\
\hline $\mathbf{o}_{\mathbf{i j}}$ & Real & Imaginary & Real & Imaginary & Real & Imaginary \\
\hline $\bar{a}_{11}$ & -0.0862 & 3.10 & 0.0119 & 3.473 & -0.0228 & 3.3506 \\
\hline $\mathrm{a}_{12}$ & 3.46 & 2.18 & 3.801 & 1.681 & 3.671 & 1.7325 \\
\hline$a_{13}$ & 3.6 & -1.69 & 3.532 & -1.185 & 3.353 & -1.9538 \\
\hline $\mathrm{Q}_{14}$ & 0.0357 & 0.766 & -0.0894 & 0.702 & 0.0319 & 0.7478 \\
\hline $\mathrm{Q}_{21}$ & -0.32 & 0.13 & -0.2695 & -0.016 & -0.2832 & 0.0083 \\
\hline $\mathrm{Q}_{22}$ & 0.37 & 2.53 & 0.227 & 2.475 & 0.244 & 2.459 \\
\hline $\mathrm{O}_{23}$ & 2.58 & -1.11 & 2.852 & -1.055 & 2.703 & -1.0507 \\
\hline $\mathrm{O}_{24}$ & -0.0359 & 0.108 & -0.0983 & 0.022 & -0.0216 & 0.0764 \\
\hline $\mathrm{Q}_{31}$ & -0.194 & 0.5525 & -0.1474 & 0.589 & -0.164 & 0.5532 \\
\hline $\mathrm{Q}_{32}$ & 0.68 & 1.45 & 0.7242 & 1.276 & 0.6824 & 1.305 \\
\hline$Q_{33}$ & 1.4 & -0.312 & 1.444 & -0.226 & 1.357 & -0.2489 \\
\hline $\mathrm{O}_{34}$ & 0.0272 & 0.0985 & .0 .0692 & 0.064 & .0 .0182 & 0.0827 \\
\hline$Q_{41}$ & -0.1135 & 0.723 & -0.3301 & -0.388 & -0.0223 & 0.8380 \\
\hline$Q_{42}$ & 0.82 & 1.00 & -0.3376 & 1.627 & 0.9066 & 0.574 \\
\hline$Q_{43}$ & 1.1 & -0.386 & 0.6071 & -0.151 & 0.9925 & -0.1059 \\
\hline$Q_{44}$ & -0.0432 & 0.232 & -0.0978 & -0.111 & -0.018 & 0.2528 \\
\hline
\end{tabular}


TABLE 5

COMPARISON OF AERODYNAMIC GENERALIZED COEFFICIENTS

$\mathrm{Q}_{\mathrm{ij}}$ FOR AGARD SWEPT WING OF ASPECT RATIO 1.45

$\mathrm{M}_{\mathrm{O}}=1.2, \mathrm{k}=1.0$

Modes: $\mathrm{q}_{1}=1.0, \mathrm{q}_{2}=\left(\mathrm{x}-\mathrm{c}_{\mathrm{r}} / 2\right), \mathrm{q}_{3}=\left(\mathrm{x}-\mathrm{c}_{\mathrm{r}} / 2\right)^{2}, \mathrm{q}_{4}=\mathrm{y}^{2}$

\begin{tabular}{|c|l|l|l|l|}
\hline Method & \multicolumn{2}{|c|}{ Present } & \multicolumn{2}{c|}{ Char. Box Ref. 20 } \\
\hline $\begin{array}{c}\text { No. of } G \\
\text { Elements }\end{array}$ & \multicolumn{2}{|c|}{6} & \multicolumn{2}{c|}{$30+$} \\
\hline $\mathrm{O}_{\mathrm{ij}}$ & Real & Imaginary & Real & Imaginary \\
\hline $\mathrm{Q}_{11}$ & -0.565 & 3.52 & -0.4042 & 3.5477 \\
$\mathrm{Q}_{12}$ & 4.12 & 1.804 & 4.0734 & 1.5832 \\
$\mathrm{Q}_{13}$ & 2.6 & -0.081 & 2.56717 & 0.15633 \\
$\mathrm{Q}_{14}$ & -0.159 & 0.785 & -0.13087 & 0.72916 \\
$\mathrm{Q}_{21}$ & -0.724 & 0.735 & -0.70852 & 0.50164 \\
$\mathrm{O}_{22}$ & 0.988 & 1.684 & 0.8165 & 1.73847 \\
$\mathrm{O}_{23}$ & 2.082 & 0.192 & 2.21076 & 0.09960 \\
$\mathrm{Q}_{24}$ & -0.216 & 0.212 & -0.17584 & 0.13608 \\
$\mathrm{O}_{31}$ & -0.376 & 0.888 & -0.33974 & 0.80848 \\
$\mathrm{O}_{32}$ & 0.962 & 0.93 & 0.91061 & 0.8632 \\
$\mathrm{O}_{33}$ & 1.238 & 0.454 & 1.19235 & 0.43602 \\
$\mathrm{O}_{34}$ & -0.153 & 0.18 & -0.12188 & 0.12959 \\
$\mathrm{Q}_{41}$ & -0.322 & 0.960 & -0.145 & 0.89538 \\
$\mathrm{Q}_{42}$ & 0.719 & 0.808 & 0.97682 & 0.52965 \\
$\mathrm{O}_{43}$ & 0.808 & 0.139 & 0.82489 & 0.23027 \\
$\mathrm{Q}_{44}$ & -0.196 & 0.297 & -0.13382 & 0.26639 \\
\hline
\end{tabular}


TABLE 6

COMPARISON OF AERODYNAMIC GENERALIZED COEFFICIENTS $Q_{i j}$

FOR AGARD SWEPT WING OF ASPECT RATIO 1.45

$\mathrm{M}_{\mathrm{o}}=2.0, \mathrm{k}=0.5$, Modes: $\mathrm{q}_{1}=1.0, \mathrm{q}_{2}=\left(\mathrm{x}-\mathrm{c}_{\mathrm{r}} / 2\right), \mathrm{q}_{3}=\left(\mathrm{x}-\mathrm{c}_{\mathrm{r}} / 2\right)^{2}, \mathrm{q}_{4}=\mathrm{y}^{2}$

\begin{tabular}{|c|c|c|c|c|c|c|}
\hline Method & \multicolumn{2}{|c|}{ Present } & \multicolumn{2}{|l|}{ Mach Box } & \multicolumn{2}{|c|}{ Characteristic Box Ref. 18} \\
\hline $\begin{array}{l}\text { No. of } \mathbf{Q} \\
\text { Elements }\end{array}$ & \multicolumn{2}{|c|}{6} & \multicolumn{2}{|c|}{$17+$} & \multicolumn{2}{|c|}{40} \\
\hline$a_{i j}$ & Rad & Imaginery & Real & Imaginary & Real & Imaginary \\
\hline $\mathrm{a}_{11}$ & 0.0698 & 2.6047 & 0.06007 & 2.565 & 0.05999 & 2.52563 \\
\hline$Q_{12}$ & 2.6094 & 0.4950 & 2.572 & 0.5374 & 2.53299 & 0.51324 \\
\hline $\mathrm{a}_{13}$ & 1.5535 & 0.6932 & 1.566 & 0.6912 & 1.51857 & 0.65485 \\
\hline $\mathrm{a}_{14}$ & -0.0121 & 0.6462 & -0.01934 & 0.5779 & -0.01374 & 0.57410 \\
\hline$a_{21}$ & -0.0057 & 0.4767 & -0.001025 & 0.4388 & -0.00307 & 0.44491 \\
\hline $\mathrm{O}_{22}$ & 0.4913 & 0.7677 & 0.45666 & 0.7695 & 0.46181 & 0.75181 \\
\hline $\mathrm{O}_{23}$ & 1.4937 & 0.2990 & 1.533 & 0.2829 & 1.48154 & 0.27395 \\
\hline $\mathrm{O}_{24}$ & -0.0230 & 0.1655 & -0.02136 & 0.01302 & -0.01853 & 0.14258 \\
\hline $\mathrm{a}_{31}$ & -0.0095 & 0.5410 & -0.00299 & 0.5293 & .0 .00676 & 0.50594 \\
\hline $\mathrm{a}_{32}$ & 0.5482 & 0.4688 & 0.5422 & 0.4457 & 0.51692 & 0.44825 \\
\hline$a_{33}$ & 0.8621 & 0.3366 & 0.8699 & 0.3102 & 0.84474 & 0.30134 \\
\hline$a_{34}$ & -0.0234 & 0.1133 & -0.01891 & 0.1028 & -0.01730 & 0.10143 \\
\hline$a_{41}$ & 0.0186 & 0.7421 & -0.1180 & -0.1415 & 0.01719 & 0.67412 \\
\hline $\mathrm{O}_{42}$ & 0.7319 & 0.2103 & -0.1348 & 0.6712 & 0.66558 & 0.19623 \\
\hline $\mathrm{O}_{43}$ & 0.5752 & 0.3510 & 0.3856 & 0.07844 & 0.53698 & 0.32057 \\
\hline $\mathbf{O}_{44}$ & -0.0224 & 0.2793 & -0.05113 & -0.03105 & -0.01956 & 0.23862 \\
\hline
\end{tabular}


TABLE 7

COMPARISON OF AERODYNAMIC GENERALIZED COEFFICIENTS $Q_{i j}$ FOR AGARD SWEPT WING OF ASPECT RATIO 1.45

$\mathrm{M}_{\mathrm{o}}=2.0, \mathrm{k}=1.4$

Modes: $q_{1}=1.0, q_{2}=\left(x-c_{r} / 2\right), q_{3}=\left(x-c_{r} / 2\right)^{2}, q_{4}=y^{2}$

\begin{tabular}{|l|l|l|l|l|}
\hline Method & \multicolumn{2}{|c|}{ Present } & \multicolumn{2}{c|}{ Mach Box Ref. 19 } \\
\hline $\begin{array}{l}\text { No. of } G \\
\text { Elements }\end{array}$ & \multicolumn{2}{|c|}{6} & \multicolumn{2}{c|}{17} \\
\hline $\mathrm{Q}_{\mathrm{ij}}$ & \multicolumn{2}{|c|}{ Real } & Imaginary & \multicolumn{2}{c|}{ Real } & Imaginary \\
\hline $\mathrm{Q}_{11}$ & -0.060 & 2.4 & -0.1529 & 2.35 \\
$\mathrm{Q}_{12}$ & 2.550 & 0.77 & 2.5010 & 0.8112 \\
$\mathrm{Q}_{13}$ & 1.511 & 0.556 & 1.480 & 0.5726 \\
$\mathrm{Q}_{14}$ & -0.134 & 0.666 & -0.1862 & 0.6014 \\
$\mathrm{O}_{21}$ & -0.336 & 0.484 & -0.3306 & 0.4262 \\
$\mathrm{Q}_{22}$ & 0.625 & 0.856 & 0.5708 & 0.8512 \\
$\mathrm{Q}_{23}$ & 1.356 & 0.28 & 1.357 & 0.2858 \\
$\mathrm{O}_{24}$ & -0.179 & 0.218 & -0.1774 & 0.1791 \\
$\mathrm{O}_{31}$ & -0.258 & 0.574 & -0.2473 & 0.5411 \\
$\mathrm{O}_{32}$ & 0.647 & 0.517 & 0.6291 & 0.4906 \\
$\mathrm{O}_{33}$ & 0.766 & 0.334 & 0.7360 & 0.3294 \\
$\mathrm{O}_{34}$ & -0.167 & 0.172 & -0.1496 & 0.1413 \\
$\mathrm{Q}_{41}$ & -0.488 & 0.682 & -0.7363 & 0.1362 \\
$\mathrm{Q}_{42}$ & 0.665 & 0.328 & 0.1201 & 0.5232 \\
$\mathrm{Q}_{43}$ & 0.625 & 0.271 & 0.2283 & 0.1796 \\
$\mathrm{Q}_{44}$ & -0.155 & 0.332 & -0.3423 & 0.00649 \\
\hline
\end{tabular}




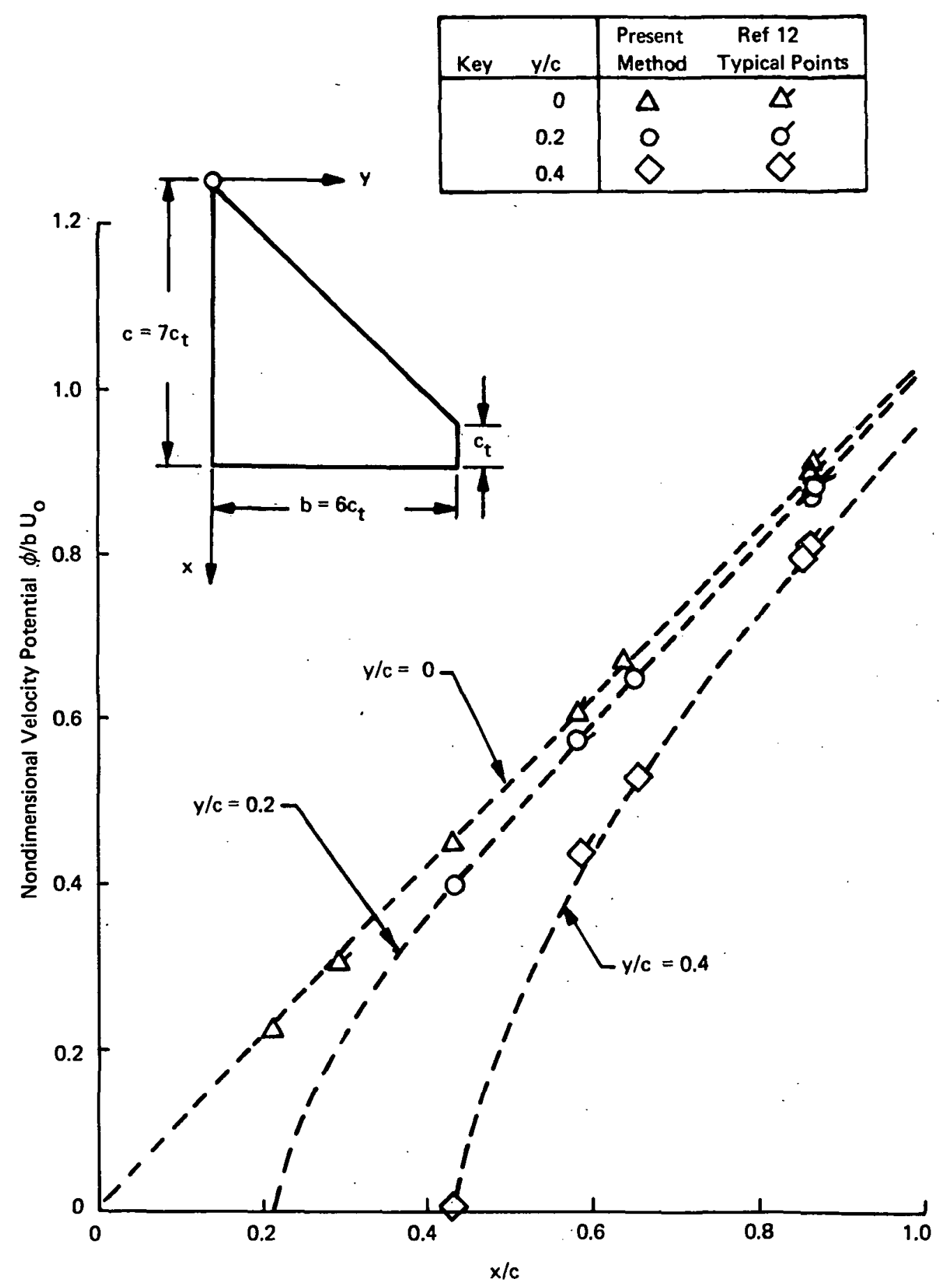

Figure 3. Velocity Potential Distribution on a Cropped Delta Wing at Constant Incidence $\mathrm{M}_{\mathrm{o}}=1.054, \mathrm{k}=0.0$ 


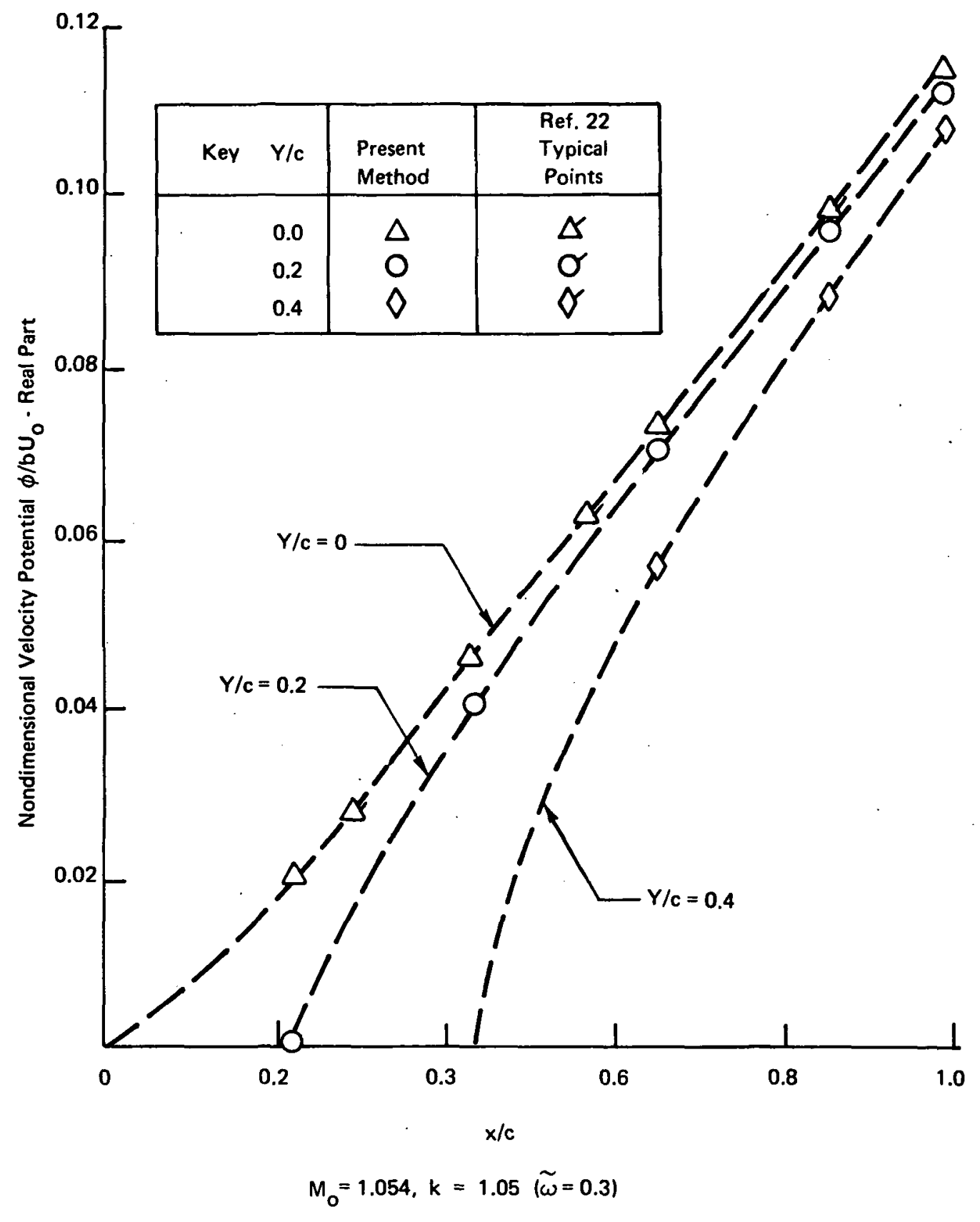

Figure 4. Real Part of Velocity Potential on a Cropped Delta Wing In Translation 


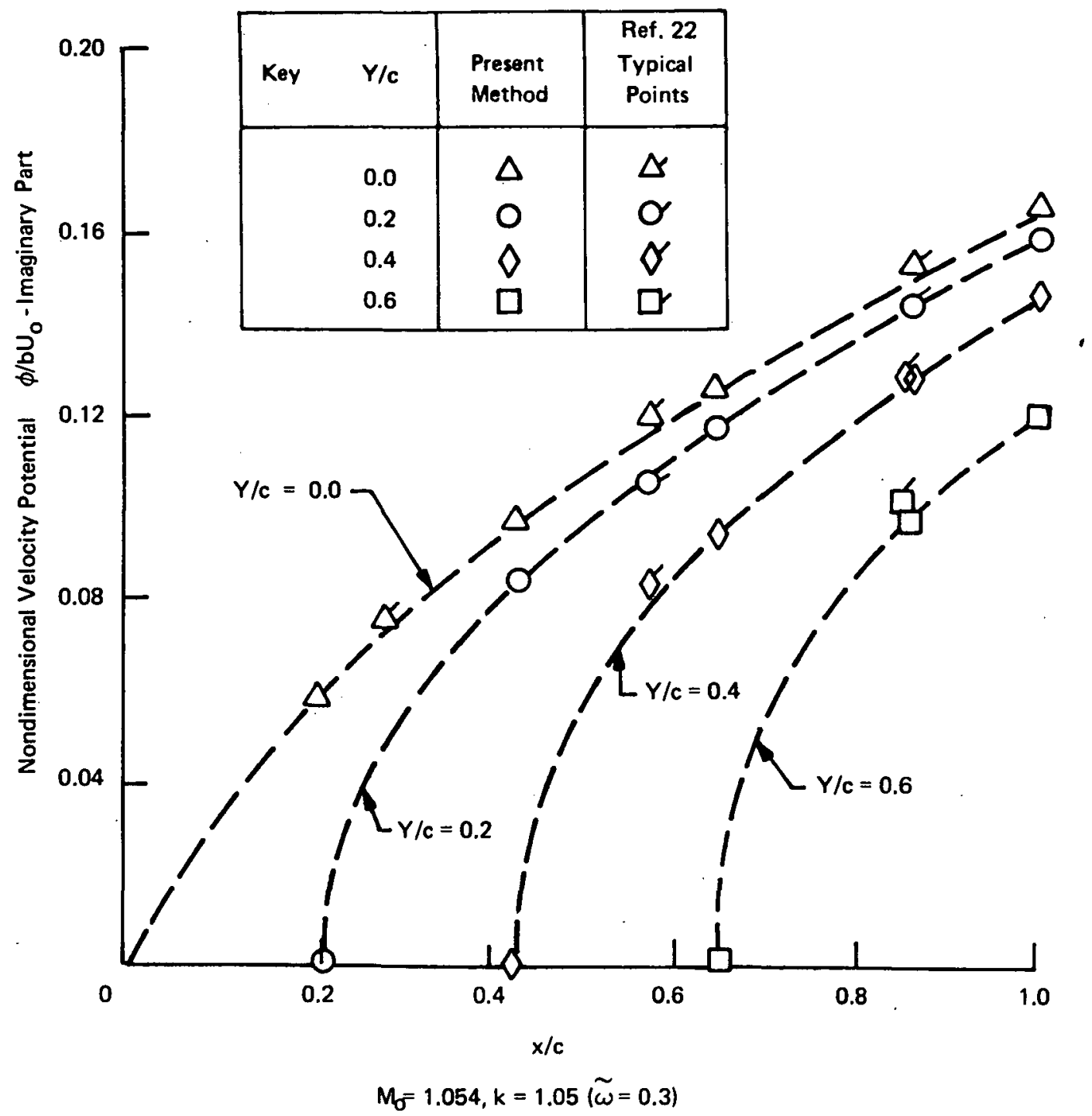

Figure 5. Imaginary Part of Velocity Potential on a Cropped Delta Wing In Translation 


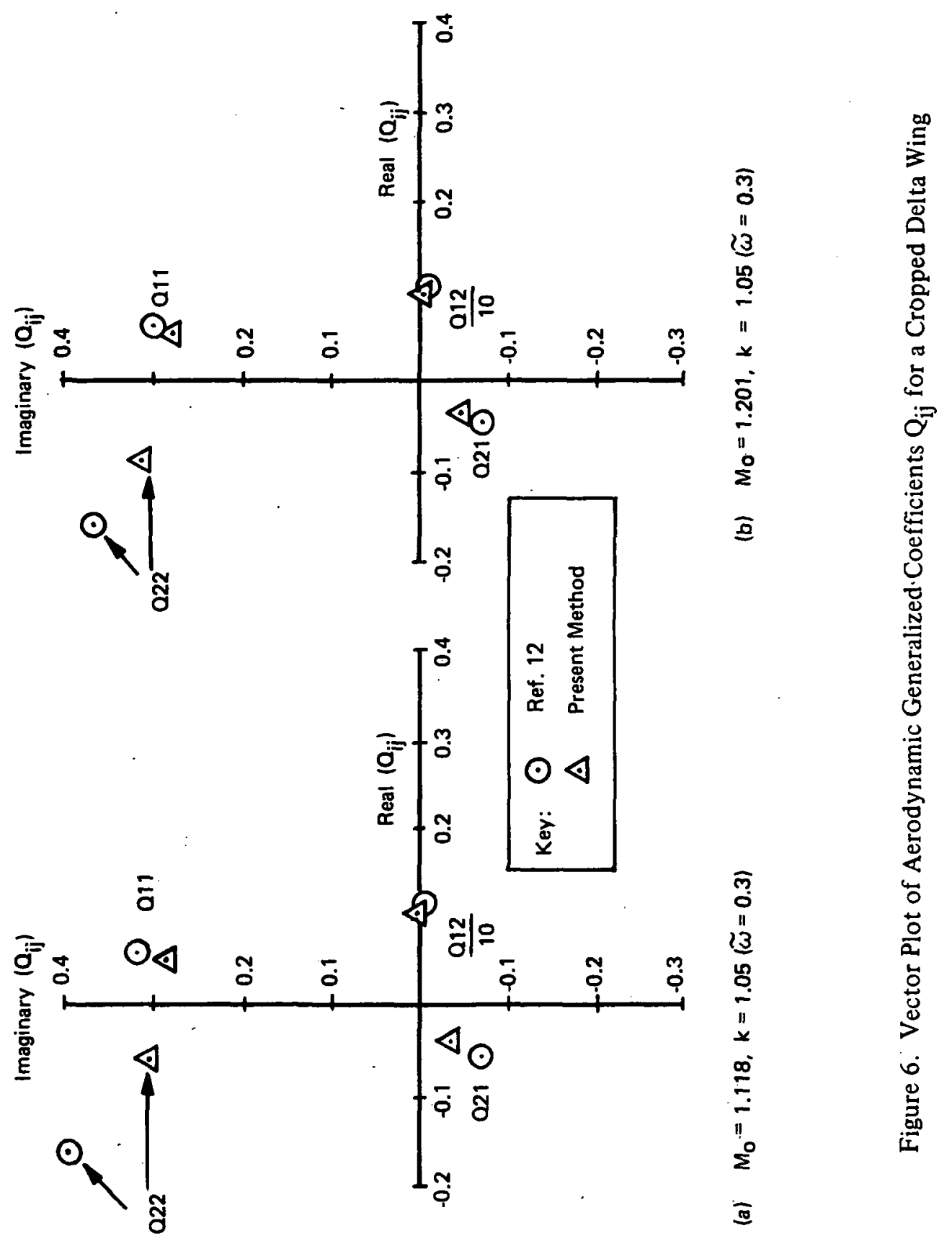




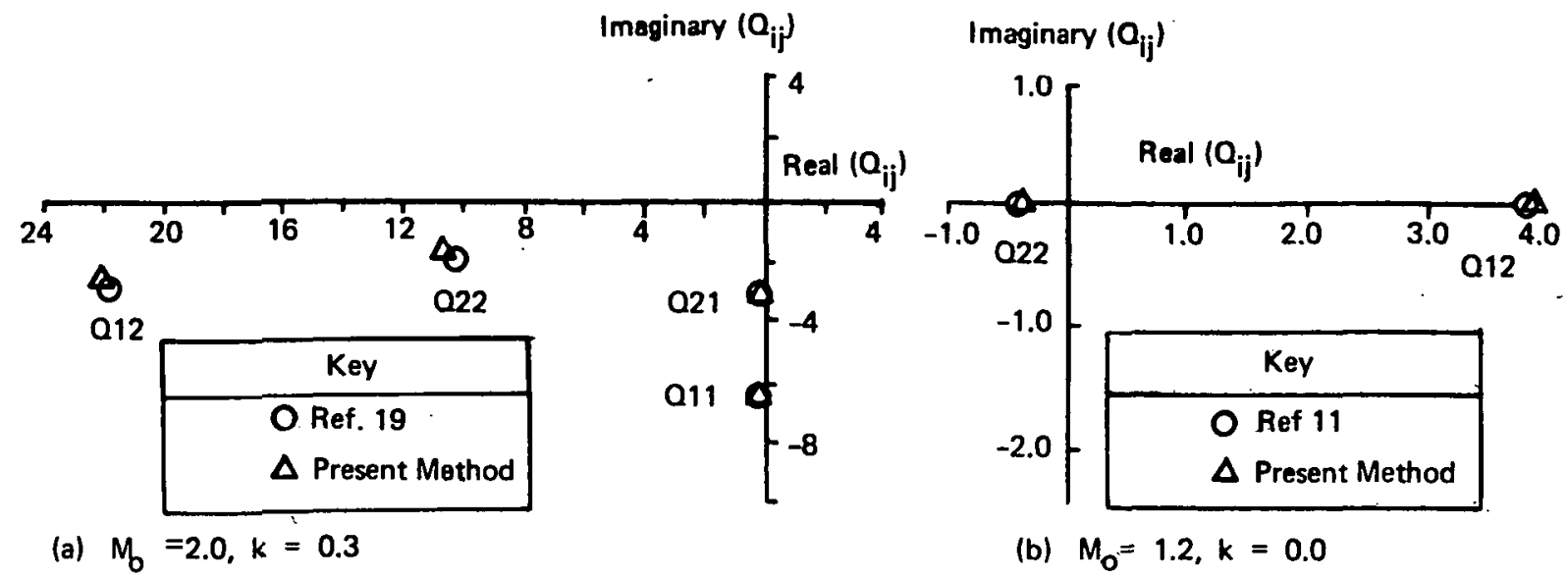

Figure 7. Vector Plot of Aerodynamic Generalized Coefficients $\mathbf{Q}_{\mathrm{ij}}$ for a Rectangular Wing of Aspect Ratio 2 
to reference frequency ratio $\left(\omega / \omega_{2}\right)$ are shown in Figure 8. Solutions obtained from supersonic kernel function and piston theories (Reference 21 ) are also shown for subsonic leading edge and supersonic leading edge cases respectively. The flutter boundary from the kernel function theory at a Mach number of 1.573 yields a conservative result while the piston theory is unconservative. The flutter boundary obtained from the consistent approach lies in between these two results, encouragingly close to the experimental flutter point. In the subsonic leading edge case, the present method gives a frequency ratio very close to the kernel function approach. In the supersonic leading edge case it suggests a transition toward piston theory solution. The experimental flutter frequency is lower than from the present solution.

\section{Interfering Wings}

Two sets of computations were made using the program for interfering wings. The first example was that considered by Woodcock and York in Reference 22. (See Figure 9.) The second (NASA example) was a combination of two tapered wings of aspect ratio 6.8 and leading edge sweep of $16.0^{\circ}$. (see Figure 10.) No experimental comparisons were available for this latter case. However, flutter calculations have been carried out to illustrate the effect of separation distance at two Mach numbers. Additionally, the effect of static deformation on flutter has been roughly assessed at one Mach number.

\section{Generalized Aerodynamics (Interfering Wing-Tail Example)}

The reference 22 wing-tail combination is shown in Figure 9. The aspect ratios of wing and tail are 2.31 and 4.62 respectively, the tail span being half the wing span. The apex of the tail is situated at $\bar{x}=2 \sqrt{3}$ and $\bar{z}=0.5$, which corresponds to $d=0.866$ and $z=0.5$ in Reference 22 . The number of elements used in Reference 22 and in the present analysis are respectively, 300 on the wing with 50 on the tail, and 49 on the wing with 16 on the tail.

Computations were made at a Mach number of 1.44 for which the wing leading edge is subsonic and the tail leading edge is supersonic. The modes are heave and pitch of the whole configuration and heave and pitch of the tail alone, the pitch axis in both cases being located at $2 / 3$ of wing root chord. The computation was performed at a reduced frequency of $k=0.01$ as in Reference 22 .

In order to give a rough indication of some of the interference effects, a few heave damping coefficients for the wing alone and tail alone are quoted from the present work, and References 22 and 23.

Results are presented in Table 8 together with corresponding figures from Reference 22, and some comparable results from Reference 24 for $\bar{z}=0$.

No objective comments are offered at this stage except that generally comparable results are obtained for coefficients of significance.

\section{Flutter of Interfering NASA Wings}

The two wings considered are of identical planform with zero stagger (See Figure 10). Aspect and taper ratios are 6.8 and 0.364 respectively, and the leading edge sweep is $16^{\circ}$.

Flutter calculations were performed at Mach numbers of 1.45 and 1.60 for various separation distances including no interference. The results are presented in two forms on Figures 11 and 12, as 

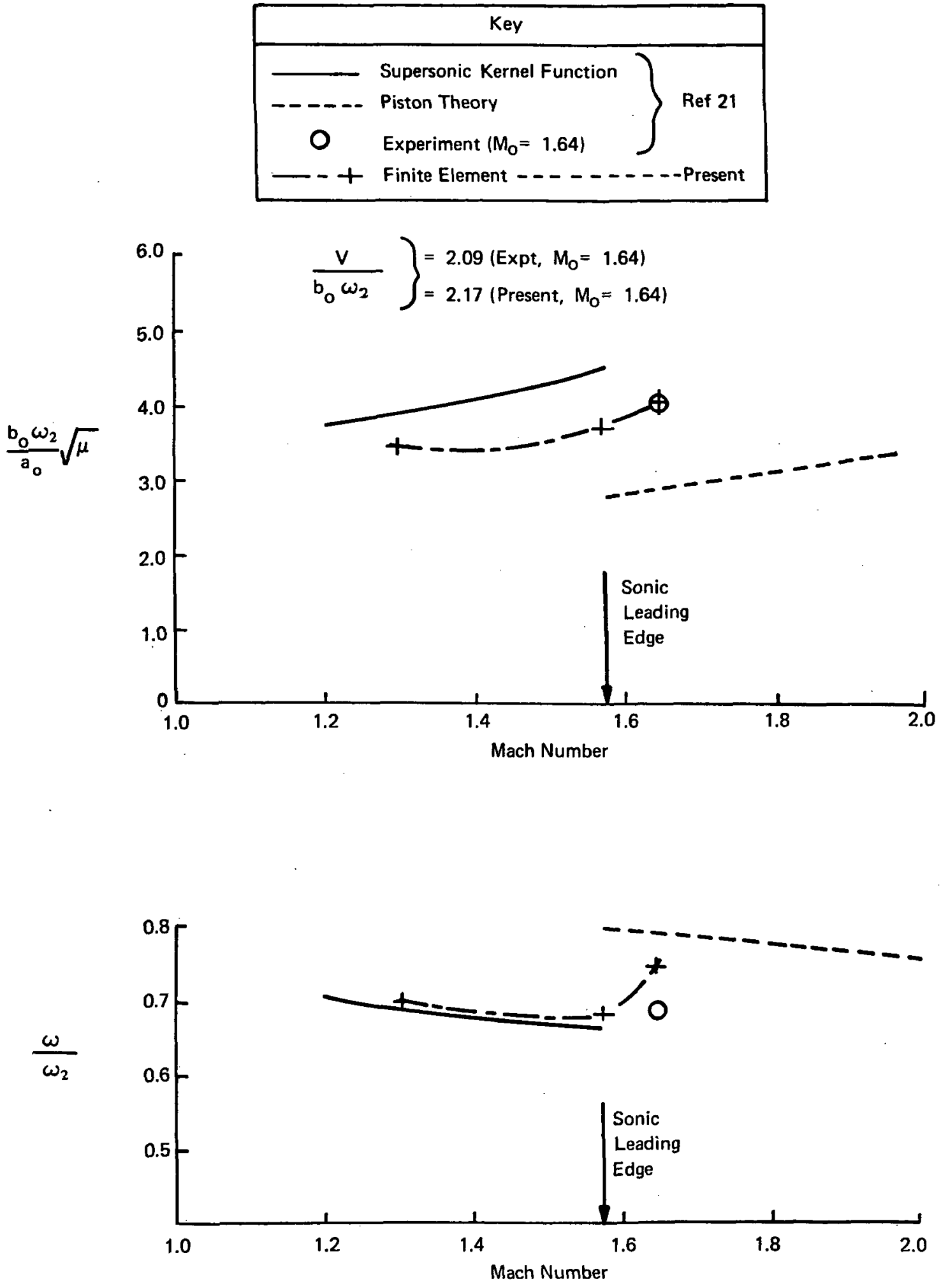

Figure 8. Flutter Boundary in Terms of the Stiffness - Altitude Parameter and Ratio of Flutter Frequency to the Second Natural Frequency versus M for HT-7 Wing 


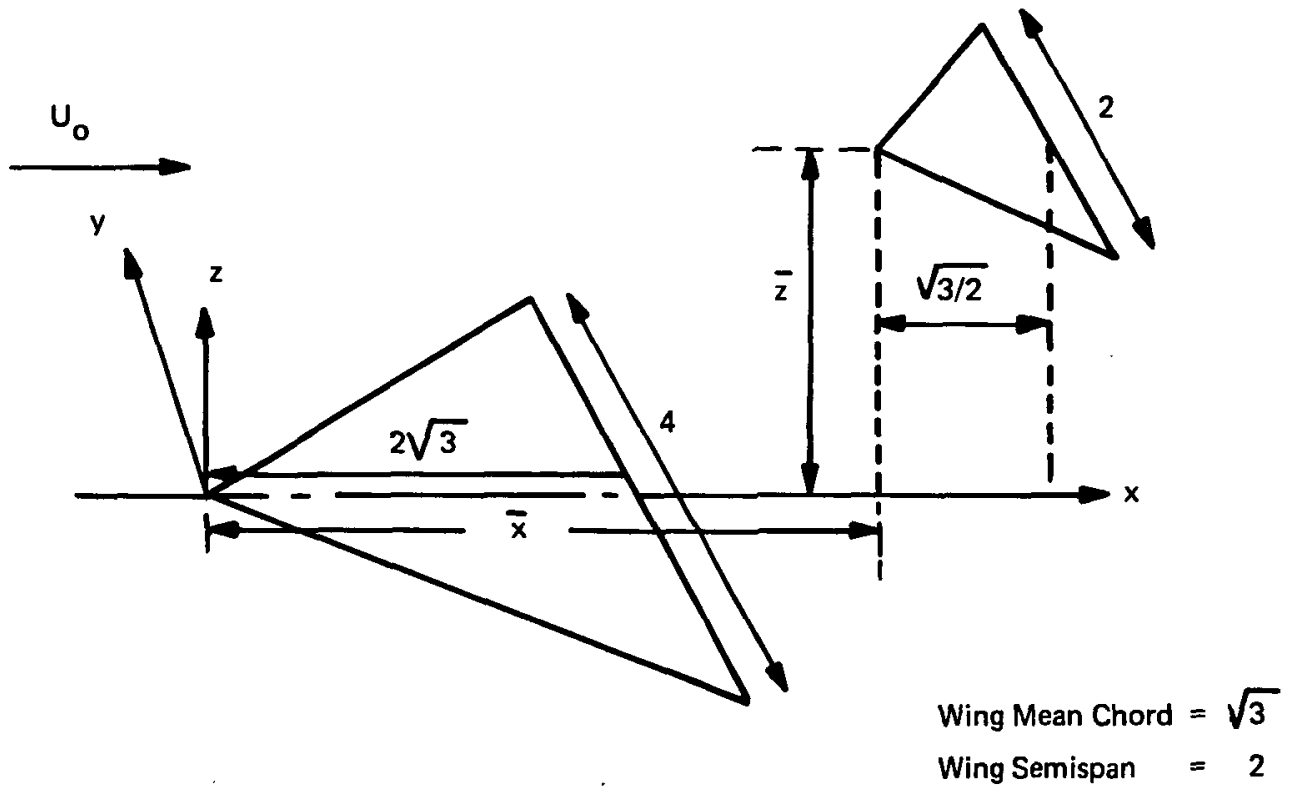

Figure 9. Configuration of Triangular Wing - Tailplane 
TABLE 8

COMPARISON OF Im. PART OF GENERALIZED DAMPING COEFFICIENTS $Q_{i j}$ FOR DELTA WING COMBINATION AT $\mathrm{M}_{\mathrm{O}}=1.44, \mathrm{k}=0.01$

$$
\begin{aligned}
\text { Modes } & 1 \text { - Heave of Wing and Tail } \\
2 & - \text { Pitch of Wing and Tail } \\
3 & - \text { Heave, Tail Only } \\
& \text { - Pitch, Tail Only }
\end{aligned}
$$

\begin{tabular}{|c|c|c|c|c|c|}
\hline \multirow{2}{*}{\multicolumn{2}{|c|}{$\begin{array}{c}\text { Method } \\
\text { Total } \\
\text { No. of } \\
\text { Elements }\end{array}$}} & Present & Ref. 22 & \multirow{2}{*}{$\begin{array}{c}\text { Ref. } 24 \\
-\end{array}$} & \multirow[t]{3}{*}{ Ref. 29} \\
\hline & & $\begin{array}{ll}\text { Wing } & 49 \\
& \\
\text { Tail } & 16\end{array}$ & $\begin{array}{ll}\text { Wing } & \mathbf{3 0 0} \\
\text { Tail } & \mathbf{5 0}\end{array}$ & & \\
\hline Im & $a_{i j}$ & 0.5 & 0.5 & 0.0 & \\
\hline & $\mathrm{o}_{11}$ & $2.6466\left(2.180^{*}\right)$ & $2.954\left(2.820^{*}\right)$ & 3.06 & $\left(2.58^{*}\right)$ \\
\hline & $\mathrm{O}_{12}$ & 0.6670 & 0.170 & 0.37 & \\
\hline & $\mathrm{Q}_{13}$ & 0.3695 & 0.477 & & \\
\hline & $\mathrm{O}_{14}$ & 0.2850 & 0.387 & & \\
\hline & $\mathrm{O}_{21}$ & 0.4280 & 0.171 & 0.21 & \\
\hline & $\mathrm{O}_{22}$ & 1.1740 & 0.934 & 1.70 & \\
\hline & $\mathrm{O}_{23}$ & 0.3741 & 0.483 & & \\
\hline & $\mathrm{O}_{24}$ & 0.2920 & 0.395 & & \\
\hline & $\mathrm{O}_{31}$ & 0.4020 & 0.148 & & \\
\hline & $\mathrm{O}_{32}$ & 0.6667 & 0.343 & & \\
\hline & $\mathrm{O}_{33}$ & 0.3696 & 0.477 & & \\
\hline & $\mathrm{O}_{34}$ & 0.2850 & 0.387 & & \\
\hline & $\mathrm{O}_{41}$ & 0.388 & 0.155 & , & \\
\hline & $\mathrm{O}_{42}$ & 0.664 & 0.358 & & \\
\hline & $\mathbf{O}_{43}$ & 0.374 & 0.483 & & \\
\hline & $\mathrm{Q}_{44}$ & 0.292 & 0.395 & & \\
\hline
\end{tabular}

"Wing Alone in Heave 


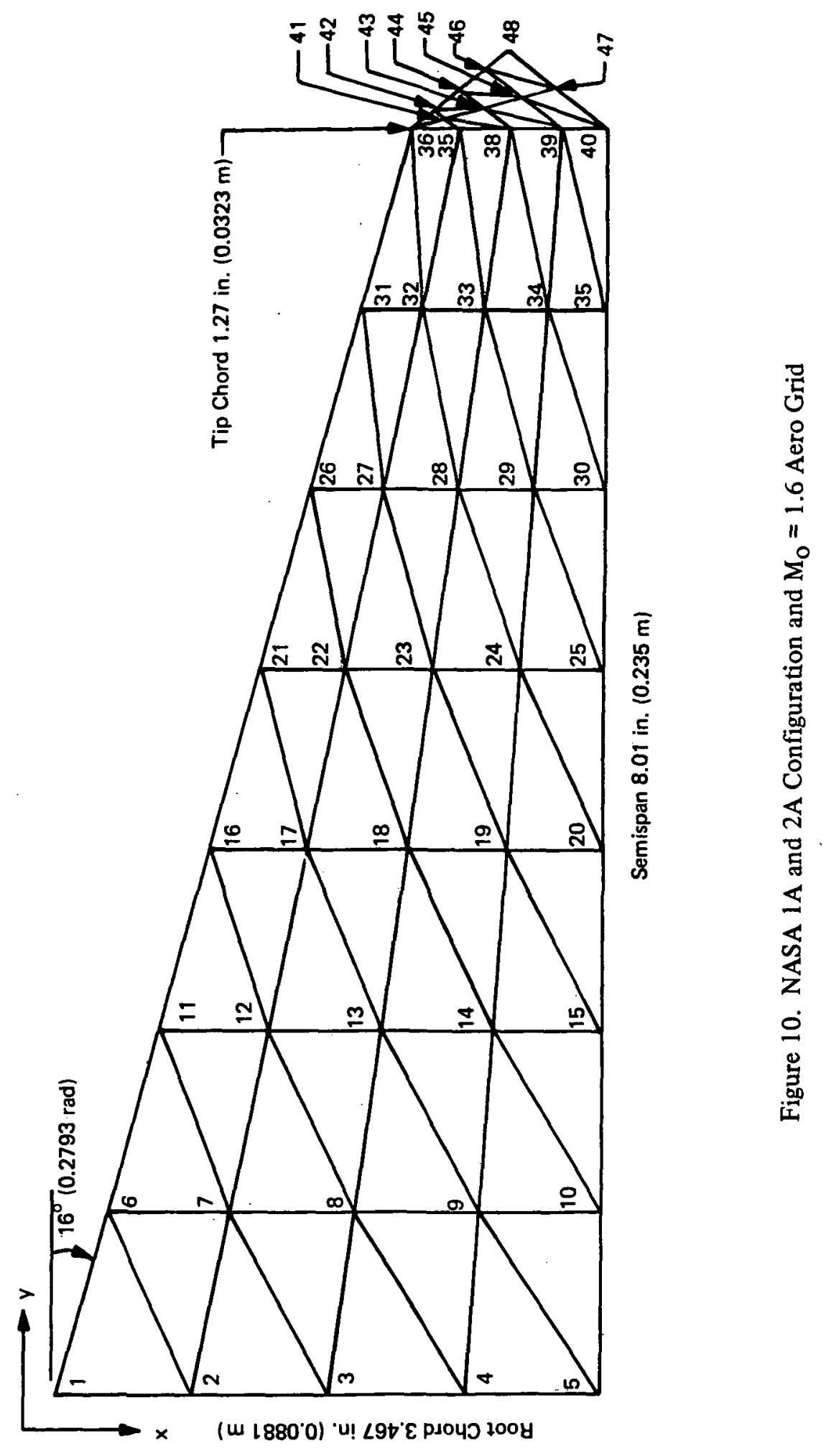


flutter speed against separation for two Mach numbers, and flutter speed against Mach number for various separation distances. Additionally at $\mathrm{M}_{\mathrm{O}}=1.60 \mathrm{only}$, the effect on flutter speeds of deflection due to thickness loading was assessed roughly. This was done by first determining the flutter dynamic pressure for zero thickness. At this dynamic pressure the steady interference loading due to thickness was determined and applied to the wings to determine their approximate deflected equilibrium positions. Flutter calculations were then repeated for these deflected positions by recomputing zero-thickness generalized forces, etc.

Modal data for unit generalized masses of the two wings are given in Tables 9A and 9B for the first four modes of each wing, these being the modes used in the flutter calculation.

Figure 11 shows the effect of separation on reduced flutter speed at $M_{0}=1.45$ and 1.60 , for which asymptotic flutter speeds without interference are 1.77 and 1.87 respectively. At $M_{O}=1.45$, interference commences at the root at a dimensionless separation of 0.95 and has spread to the tip at a separation of 0.348 . At $M_{o}=1.60$, the separations are 0.80 for the root and 0.293 for the tip interference.

The results for $M_{o}=1.60$ suggest that the effect of interference, which starts at the root, is first small, as might be expected. As the inteference effect reaches beyond mid-span, the flutter speed falls much more rapidly, the rate of fall decreasing again as the interference effect spreads out to the tip. The same general conclusions hold for $\mathrm{M}_{\mathrm{O}}=1.45$. However, at this Mach number the total reduction in flutter speed is more drastic and is probably affected by the shortcomings of linearized theory which predicts negative two-dimensional aerodynamic damping for a range of reduced frequency below $\mathrm{M}_{\mathrm{O}}=\sqrt{2}$. The wings in the present example are not too far removed from the unswept-two-dimensional case.

Figure 12 crossplots flutter speed against Mach number and also sketches the asymptotic noninterference boundary.

Both Figures 11 and 12 include the effect on flutter speed at $M_{o}=1.6$ of the static interference. The effect is small and the single iteration used for static deflection is probably adequate. This effect has not been determined for $\mathrm{M}_{\mathrm{O}}=1.45$.

An interesting feature of the flutter modal vector behavior was noticed as the separation decreased. Without interference, the thinner, lower frequency Wing $1 \mathrm{~A}$ fluttered at a lower reduced speed than Wing $2 \mathrm{~A}$ (i.e., at 1.87 and 1.77 for Mach numbers of 1.60 and 1.45 respectively -see Figure 11). The flutter mode was dominated by Mode 3, its first torsion mode.

However, for the smallest separation case $\left(\frac{Z}{2 b}=0.214\right)$ of the Mach 1.60 calculations, the flutter mode and frequency were dominated by the thicker wing $2 \mathrm{~A}$. The flutter frequency was 2837 rps compared to the zero airspeed Wing 2 A Mode 3 (torsion) frequency of 2819 rps.

The significant contributions to the modal vector were:

$$
\begin{array}{lll}
\text { Wing 1 A } & - \text { Mode } 3 \text { (first torsion) }+0.080 \\
\text { Wing 2A } & - \text { Mode } 1 \text { (first bending) }-0.083 \\
& \text { Mode } 3 \text { (first torsion) }+0.928
\end{array}
$$


TABLE 9A

MODE SHAPES AND FREQUENCIES FOR NASA WING MODEL 1 A

\begin{tabular}{|c|c|c|c|c|}
\hline Mode & 1 & 2 & 3 & 4 \\
\hline Frequency & 346.0.rps & $1290.0 . \mathrm{rps}$ & $2121.4 \mathrm{rps}$ & $3169.0 \mathrm{rps}$ \\
\hline Grid Point & - & - & - & - \\
\hline 1 & 0.0 & 0.0 & 0.0 & 0.0 \\
\hline 2 & $-0.248374 E \quad 00$ & $0.846053 E 00$ & $0.340652 E \quad 00$ & $0.156274 E \quad 01$ \\
\hline 3 & 0.0 & 0.0 & 0.0 & 0.0 \\
\hline 4 & $-0.661762 E \quad 00$ & $-0.132569 E \quad 01$ & $-0.162827 E \quad 02$ & $-0.955371 E \quad 01$ \\
\hline 5 & $-0.148843 E \quad 01$ & $-0.574492 E \quad 01$ & $-0.501730 \mathrm{E} \quad 02$ & -0.306777 E 02 \\
\hline 6 & $0.373210 E$ O1 & $-0.110920 E \quad 02$ & $0.256854 E \quad 02$ & -0.238349 E 02 \\
\hline 7 & $0.510167 E \quad 01$ & $-0.15107 .2 E \quad 02$ & $0.166748 E \quad 02$ & $-0.290629 E \quad 02$ \\
\hline 8 & $0.600098 E \quad 01$ & $-0.188923 E \quad 02$ & $-0.383127 E 01$ & $-0.338759 E \quad 02$ \\
\hline $\mathbf{g}$ & $0.714894 E \quad 01$ & $-0.260340 E \quad 02$ & $-0.358998 E \quad 02$ & -0.482695 E 02 \\
\hline 10 & $0.751287 E 01$ & $-0.329570 \mathrm{E} \quad 02$ & $-0.752936 E \quad 02$ & $-0.650456 \mathrm{E} \quad 02$ \\
\hline 11 & $0.144421 E \quad 02$ & $-0.377111 E 02$ & $0.664367 E \quad 02$ & $-0.624758 E \quad 02$ \\
\hline 12 & $0.168970 \mathrm{E} 02$ & $-0.433420 \mathrm{E} \quad 02$ & $0.358953 E \quad 02$ & -0.625167 E 02 \\
\hline 13 & $0.189125 E \quad 02$ & $-0.494378 E \quad 02$ & $-0.280577 E 01$ & $-0.635001 E \quad 02$ \\
\hline 14 & $0.202884 E \quad 02$ & $-0.557970 E \quad 02$ & $-0.480677 E \quad 02$ & $-0.659036 \mathrm{E} \quad 02$ \\
\hline 15 & $0.210618 E \quad 02$ & $-0.629261 E \quad 02$ & $.0 .969772 \mathrm{E} \quad 02$ & $-0.717563 E \quad 02$ \\
\hline 16 & $0.327125 E \quad 02$ & $-0.656615 \mathrm{E} \quad 02$ & $0.107401 E \quad 03$ & $-0.631332 E \quad 02$ \\
\hline 17 & $0.356679 E \quad 02$ & $.0 .688935 E \quad 02$ & $0.594811 E \quad 02$ & -0.503386 E 02 \\
\hline 18 & $0.380185 E \quad 02$ & $-0.728230 \mathrm{E} \quad 02$ & 0.537178E 01 & $-0.379178 E \quad 02$ \\
\hline 19 & $0.397843 E 02$ & $-0.779427 E \quad 02$ & $-0.530814 E \quad 02$ & $-0.274941 E \quad 02$ \\
\hline 20 & $0.409142 E \quad 02$ & -0.844757 E 02 & -0.113283 E 03 & $-0.197513 E 02$ \\
\hline 21 & $0.584188 E \quad 02$ & $-0.713794 E \quad 02$ & 0.142117 E 03 & $-0.106175 E 01$ \\
\hline 22 & $0.614552 E \quad 02$ & $-0.701302 E \quad 02$ & $0.804984 E \quad 02$ & $0.196408 E \quad 02$ \\
\hline 23 & $0.639868 E \quad 02$ & $-0.705903 E \quad 02$ & $0.145253 E \quad 02$ & $0.402410 E \quad 02$ \\
\hline 24 & $0.659998 \mathrm{E} \quad 02$ & $-0.730238 E \quad 02$ & $-0.541276 E \quad 02$ & $0.602483 E \quad 02$ \\
\hline 25 & $0.674978 E 02$ & $\cdot 0.777540 E \quad 02$ & $-0.123549 E \quad 03$ & $0.794476 E \quad 02$ \\
\hline 26 & $0.912201 E \quad 02$ & $-0.310397 E \quad 02$ & $0.158395 \mathrm{E} \quad 03$ & 0.598651E 02 \\
\hline 27 & $0.940856 E \quad 02$ & $-0.257317 E \quad 02$ & $0.883828 E \quad 02$ & $0.758822 E \quad 02$ \\
\hline 28 & $0.965729 E .02$ & $-0.226300 E \quad 02$ & $0.157768 E \quad 02$ & $0.941429 E \quad 02$ \\
\hline 29 & $0.986789 E \quad 02$ & $-0.219322 E \quad 02$ & $-0.581623 E 02$ & $0.114858 E \quad 03$ \\
\hline 30 & $0.100418 \mathrm{E} \quad 03$ & $-0.237869 E \quad 02$ & $-0.132125 E \quad 03$ & $0.138293 E \quad 03$ \\
\hline 31 & $0.129880 E \quad 03$ & $0.676545 E \quad 02$ & $0.144149 \mathrm{E} \quad 03$ & $-0.820722 \mathrm{E} \quad 01$ \\
\hline 32 & 0.132357 E 03 & 0.748086 E 02 & $0.730007 E 02$ & $-0.304004 E 01$ \\
\hline 33 & 0.134593 E 03 & $0.798729 E \quad 02$ & $0.785800 E \quad 00$ & $0.718163 E \quad 01$ \\
\hline 34 & $0.136588 E \quad 03$ & 0.827491E 02 & $-0.717218 E \quad 02$ & $0.229209 E \quad 02$ \\
\hline 35 & $0.138360 \mathrm{E} \quad 03$ & 0.834467E 02 & $-0.143789 E \quad 03$ & $0.443335 E \quad 02$ \\
\hline 36 & $0.171953 E \quad 03$ & $0.210059 \mathrm{E} \quad 03$ & $0.989585 E \quad 02$ & $-0.242098 E \quad 03$ \\
\hline 37 & $0.173924 E \quad 03$ & $0.216496 \mathrm{E} \quad 03$ & 0.345747 E 02 & $-0.241725 E \quad 03$ \\
\hline 38 & $0.175761 E \cdot 03$ & $0.221376 E \quad 03$ & -0.298829 E $\quad 02$ & $-0.235332 \mathrm{E} \quad 03$ \\
\hline 39 & $0.177465 E \quad 03$ & $0.224694 \mathrm{E} \quad 03$ & $-0.941044 E \quad 02$ & $-0.222813 E \quad 03$ \\
\hline 40 & $0.179052 \mathrm{E} \quad 03$ & $0.226521 E \quad 03$ & $-0.157824 E \quad 03$ & -0.204166 E $\quad 03$ \\
\hline
\end{tabular}


TABLE 9B

MODE SHAPES AND FREQUENCIES FOR NASA WING MODEL $2 A$

\begin{tabular}{|c|c|c|c|c|}
\hline Mode & 1 & 2 & 3 & 4 \\
\hline Frequency & $476.6 \mathrm{rps}$ & 1716.0 rps & 2819 rps & 4211 rps \\
\hline Grid Points & - & - & - & - \\
\hline 1 & 0.0 & 0.0 & 0.0 & 0.0 \\
\hline 2 & $-0.216321 E \quad 00$ & $0.733357 \mathrm{E} 00$ & $0.293900 E \quad 00$ & $0.134361 E 01$ \\
\hline 3 & 0.0 & 0.0 & 0.0 & 0.0 \\
\hline 4 & $-0.576453 E \quad 00$ & $-0.115600 E 01$ & $-0.141411 E \quad 02$ & $-0.832933 E \quad 01$ \\
\hline 5 & $-0.129031 E 01$ & $-0.500474 \mathrm{E} 01$ & $-0.435684 E \quad 02$ & $-0.266567 E \quad 02$ \\
\hline 6 & $0.323887 E 01$ & $-0.962833 E 01$ & $0.222815 E \quad 02$ & $-0.207137 \mathrm{E} \quad 02$ \\
\hline 7 & $0.442801 E 01$ & $-0: 131154 E 02$ & $0.144487 E \quad 02$ & $-0.252496 E \quad 02$ \\
\hline 8 & O.520807E 01 & $-0.163985 E \quad 02$ & $-0.333866 \mathrm{E} \quad 01$ & $-0.294104 E \quad 02$ \\
\hline 9 & $0.620506 E \quad 01$ & -0.225997 E 02 & $.0 .311611 E \quad 02$ & $-0.418901 E \quad 02$ \\
\hline 10 & $0.652201 E \quad 01$ & $-0.286114 E 02$ & $.0 .653320 \mathrm{E} \quad 02$ & $-0.564257 E \quad 02$ \\
\hline 11 & $0.125306 \mathrm{E} \quad 02$ & $-0.327159 E \quad 02$ & $0.576116 \mathrm{E} \quad 02$ & $-0.542299 E \quad 02$ \\
\hline 12 & 0.146600 E 02 & $-0.375993 E 02$ & $0.311273 E \quad 02$ & $-0.542434 E \quad 02$ \\
\hline 13 & 0.164083 E 02 & $-0.428873 E 02$ & $-0.244496 \mathrm{E} 01$ & $-0.550728 E \quad 02$ \\
\hline 14 & 0.176038 E 02 & -0.484108 E 02 & $-0.417061 E \quad 02$ & $-0.571416 \mathrm{E} \quad 02$ \\
\hline 15 & $0.182764 E \quad 02$ & $-0.546015 E 02$ & $-0.841242 E \quad 02$ & $-0.621955 E \quad 02$ \\
\hline 16 & $0.283770 E \quad 02$ & $-0.569429 E \quad 02$ & 0.931467E 02 & $-0.547628 E \quad 02$ \\
\hline 17 & $0.309410 E 02$ & $-0.597486 \mathrm{E} \quad 02$ & $0.515929 E \quad 02$ & $-0.436474 E \quad 02$ \\
\hline 18 & $0.329810 E \quad 02$ & $-0.631616 \mathrm{E} \quad 02$ & $0.466318 E \quad 01$ & $-0.328564 E \quad 02$ \\
\hline 19 & $0.345137 E \quad 02$ & $-0.676064 \mathrm{E} \quad 02$ & $-0.460318 E \quad 02$ & $-0.237896 E \quad 02$ \\
\hline 20 & $0.354956 \mathrm{E} \quad 02$ & $-0.732784 \mathrm{E} \quad 02$ & $-0.982352 E \quad 02$ & $\cdot 0.170476 \mathrm{E} \quad 02$ \\
\hline 21 & $0.506714 E \quad 02$ & $-0.618871 E \quad 02$ & $0.123267 E \quad 03$ & $-0.918818 E \quad 00$ \\
\hline 22 & $0.533058 \mathrm{E} \quad 02$ & $-0.608072 E \quad 02$ & $0.698350 E \quad 02$ & $0.170479 \mathrm{E} \quad 02$ \\
\hline 23 & $0.555023 E \quad 02$ & $-0.612102 E \quad 02$ & $0.126208 E \quad 02$ & $0.349313 E \quad 02$ \\
\hline 24 & $0.572493 E \quad 02$ & $-0.633248 E 02$ & $-0.469159 E \quad 02$ & $0.523054 E \quad 02$ \\
\hline 25 & $0.585499 E \quad 02$ & -0.674306 E 02 & $-0.107110 \mathrm{E} 03$ & $0.689820 \mathrm{E} \quad 02$ \\
\hline 26 & $0.791174 E \quad 02$ & $-0.268896 E \quad 02$ & $0.137385 E \quad 03$ & $0.518804 E \quad 02$ \\
\hline 27 & $0.816033 E \quad 02$ & $-0.222904 \mathrm{E} \quad 02$ & $0.766725 E \quad 02$ & $0.657801 \mathrm{E} 02$ \\
\hline 28 & $0.837612 E \quad 02$ & $-0.196051 E \quad 02$ & $0.137075 E \quad 02$ & $0.816333 E \quad 02$ \\
\hline 29 & $0.855884 E \quad 02$ & $-0.190043 E 02$ & $\cdot 0.504115 E \quad 02$ & $0.996200 \mathrm{E} \quad 02$ \\
\hline 30 & $0.870982 E \quad 02$ & $-0.206159 E \quad 02$ & $-0.114543 E \quad 03$ & $0.119965 \mathrm{E} \quad 03$ \\
\hline 31 & $0.112643 E \quad 03$ & $0.587043 E 02$ & $0.125004 E \quad 03$ & $-0.721169 E \quad 01$ \\
\hline 32 & $0.114791 E \quad 03$ & $0.649023 E \quad 02$ & $0.633012 E \quad 02$ & $-0.270577 E 01$ \\
\hline 33 & $0.116731 E \quad 03$ & $0.692881 E \quad 02$ & $0.672285 E 00$ & $0.618898 E \quad 01$ \\
\hline 34 & $0.118462 E \quad 03$ & $0.717767 E \quad 02$ & $-0.662088 E \quad 02$ & $0.198692 \mathrm{E} \quad 02$ \\
\hline 35 & $0.119999 E \quad 03$ & $0.723772 E \quad 02$ & $-0.124703 E \quad 03$ & $0.384641 \mathrm{E} \quad 02$ \\
\hline 36 & $0.149126 E \quad 03$ & $0.182181 E \quad 03$ & $0.857724 E \quad 02$ & $-0.210011 E \quad 03$ \\
\hline 37 & $0.150836 E \quad 03$ & 0.187757 E 03 & $0.299216 E 02$ & $-0.209643 E \quad 03$ \\
\hline 38 & $0.152429 E \quad 03$ & $0.191982 E \quad 03$ & $-0.259948 E \quad 02$ & $-0.204055 E \quad 03$ \\
\hline 39 & $0.153908 E \quad 03$ & $0.194855 E \quad 03$ & $-0.817059 \mathrm{E} \quad 02$ & $-0.193157 E \quad 03$ \\
\hline 40 & $0.155284 E \quad 03$ & 0.196436 E 03 & $-0.136979 E \quad 03$ & $-0.176952 E \quad 03$ \\
\hline
\end{tabular}




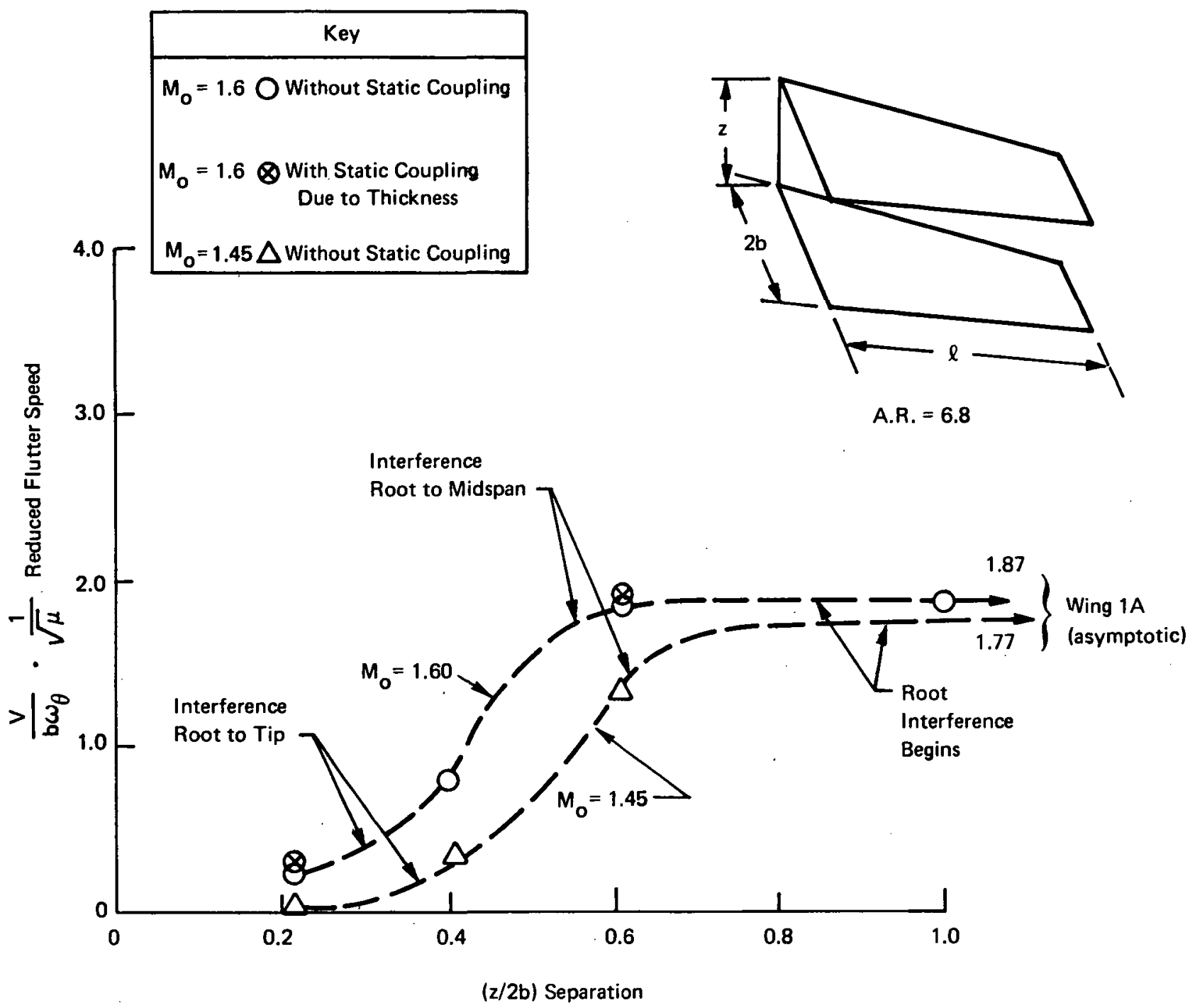

Figure 11. Variation of Reduced Flutter Speed with Vertical Separation at $M_{0}=1.45$ and $M_{0}=1.6$ 


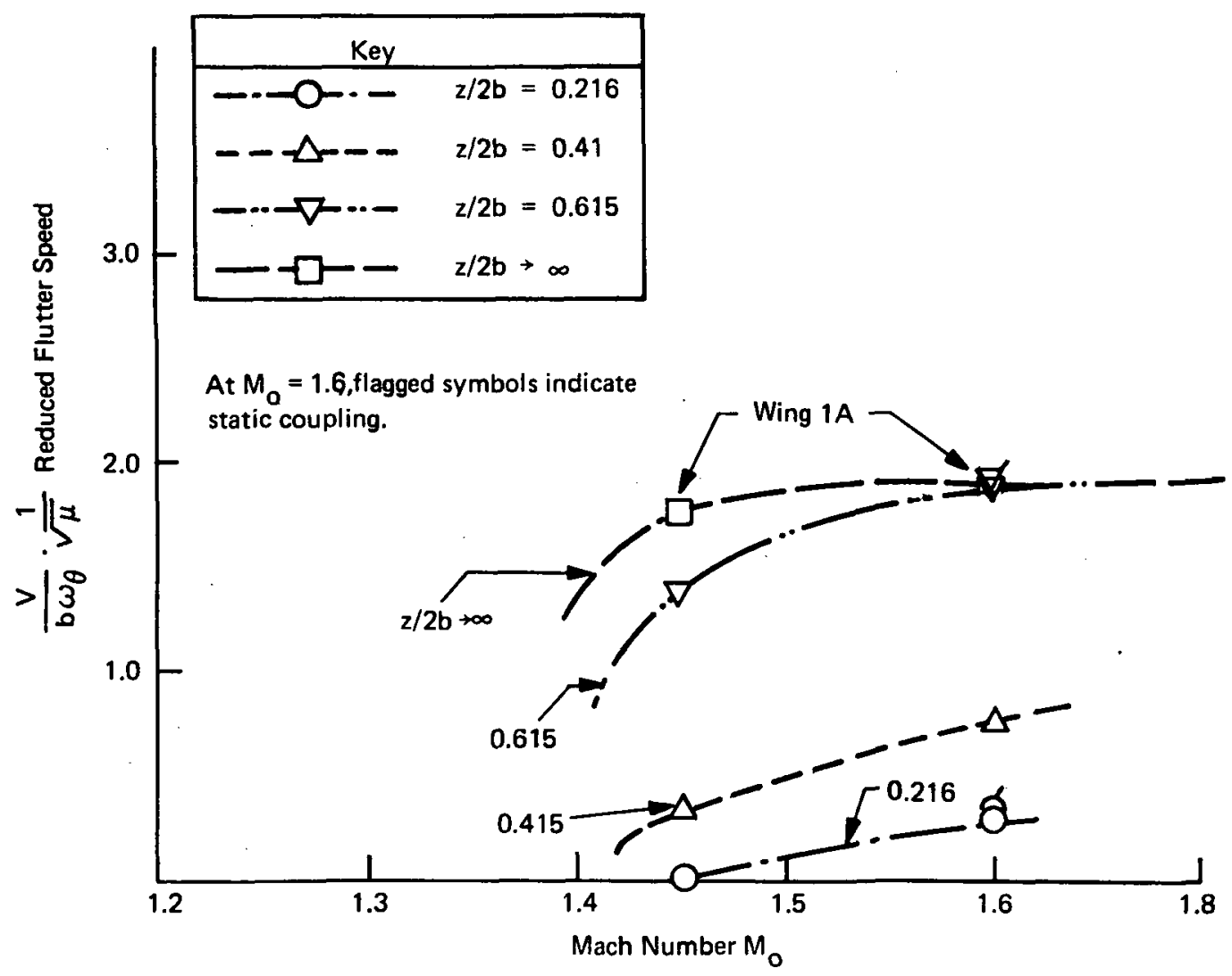

Figure 12. Variation of Reduced Flutter Speed with Vertical Separation

(Cross-Plot of Figure 11) 


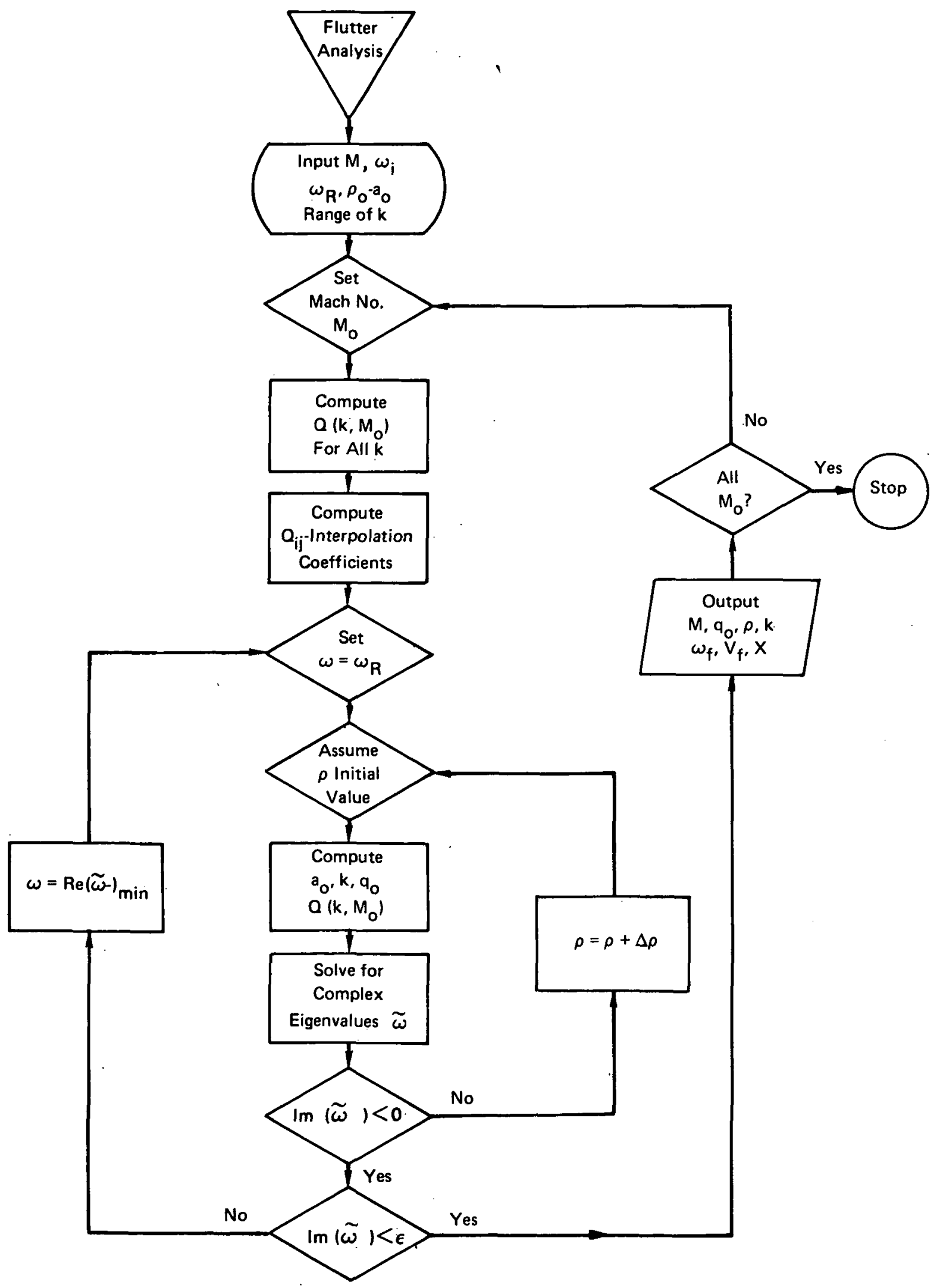

Figure 13. Flow Chart for Flutter Analysis 


\section{CONCLUSIONS AND RECOMMENDATIONS}

Further applications of an improved consistent approach to the derivation of unsteady aerodynamic forces for planar wings have been illustrated, and an operational computer program produced. Similar techniques have been developed for nearly parallel interfering planar wings, and an operational program has been used for the study of flutter characteristics of a pair of wings as affected by separation and steady airload deflection effects.

In general terms, it appears that the approximations made in satisfying boundary conditions for interfering wings are warranted for the limited range of applications considered, but further evidence of their validity should be obtained as more comparative numerical examples become available.

The encouraging comparisons with References $11,12,19$ and 20 confirm general conclusions concerning the advantages of the present approach in reducing the numerical size of matrix equations necessary for acceptable accuracy.

With respect to the excellent experimental flutter correlation obtained in Figure 8, the example stands alone and requires further applications before general conclusions are possible. The same remarks apply concerning the Kernel Function - Piston Theory transition noted in the text.

The interference algorithm has illustrated the probability of strong detrimental effects of proximity on the flutter of interfering wings.

The flutter algorithm used offers potential for more direct computer operator interaction than more common approaches and is worthy of additional development.

The present programs are not optimally designed from the computer time point of view, but have generally evolved with the developments reported. No computer time comparisons with Reference 22 are available, for example, but again, the marked difference in grid sizes is apparent.

The expansion of the present approach to include more complex interacting and interfering configurations, subsonic trailing edges and interfering wakes is feasible. It is probable that the present approach will be even more advantageous from the numerical point of view in these more complex circumstances. The basic method could additionally be reformulated in terms of an intergrated potential approach (References 25-27) avoiding the use of diaphragms.

An iterative form of static aeroelastic solution for deforming, interacting surfaces is feasible. In these problems, the domain of dependence of a particular point may alter significantly with the "static" deformation, and require an iterative type solution to the resulting equation. Flutter solutions could continue to be determined as linearized problems about the static equilibrium position. 


\section{APPENDIX}

Derivation and numerical integration of the velocity potential and downwash matrices for basic triangular elements are described in this section. Details of the programming for the solution of the total problem are contained in Reference 28.

\section{Velocity Potential - Isolated Wing}

For thin wings in supersonic flow, the nondimensional source distribution due to perturbed motion from Eq. (26) is given by

$$
\sigma\left(\Xi_{\mathrm{i}}\right)=\frac{\mathrm{w}\left(\Xi_{\mathrm{i}}\right)}{\mathrm{U}}=\left[\bar{\lambda} \Omega(\Xi)+\Omega_{\xi}\right] \rho_{\mathrm{j}}
$$

where the interpolation matrix $\Omega\left(\Xi_{\mathrm{i}}\right)$ for the triangular element is

$$
\Omega(\Xi)=[\xi, \eta, 1] \mathbf{T}
$$

in which $\quad \mathbf{T}=\left[\begin{array}{lll}\xi_{1} & \eta_{1} & 1 \\ \xi_{2} & \eta_{2} & 1 \\ \xi_{3} & \eta_{3} & 1\end{array}\right]^{-1}$

and $\Omega_{\xi}=\frac{\partial \Omega}{\partial \xi}=\left[\begin{array}{lll}1 & 0 & 0\end{array}\right] \mathbf{T}$

Using the source displacement relation given by Eqn. (A-1) in Eqn. (4), the velocity potential irtfluence coefficient matrix relating nodal source strengths to nodal displacements can be written similar to Eqn. (11) as

$$
\Phi_{\mathrm{ij}}=\frac{1}{\pi} \iint_{\mathrm{S}_{\mathrm{j}}} \mathrm{F}\left(\mathrm{X}_{\mathrm{i}}, \Xi_{\mathrm{j}}\right)\left[\bar{\lambda} \Omega+\Omega_{\xi}\right] \mathrm{dS}
$$

(Note the distinctive definitions of $\Phi_{\mathrm{ij}}$ for isolated and interfering wings).

Integration of Eqn. (A-5) is performed numerically using Gaussian 5-point quadrature coefficients. The elements cut by Mach lines emerging from the position $\mathrm{X}_{\mathrm{i}}$ were truncated by a small width and integrated analytically using characteristic coordinates. More detailed information is contained in Reference 13.

\section{Velocity Potential - Interfering Wings}

For interfering wings the source distribution is not known until the kinematic boundary conditions as given by Eqn. (13) are satisfied. This requires the normal derivative of the velocity potential. When this is performed the kernel $F$ in Eqn. (5) will exhibit a higher order singularity which usually requires more elaborate numerical integration. However, this situation can be avoided by using the equality credited to Watson (References 8 and 11),

$$
\frac{\cos \left(\frac{\hat{\mathrm{k}}_{\mathrm{M}}}{\mathrm{M}_{\mathrm{\mu}}-\nu^{2}}\right)}{\sqrt{\mu^{2}-\nu^{2}}}=-\frac{\partial}{\partial \nu}(\psi(\mu, \nu))
$$


where $\left.\mu^{2}=(\mathrm{x}-\xi)^{2}-\beta^{2}(\mathrm{z}-\zeta)^{2}\right\}$

$\nu=\beta(y-\eta)$

$$
\left.\begin{array}{l}
\hat{k}=\frac{\mathrm{kM}_{\mathrm{o}}^{2}}{\beta^{2}} \\
\mathrm{k}=\frac{\omega \ell}{\mathrm{U}}
\end{array}\right\}
$$

and $\psi(\mu, \nu)=\mathrm{J}_{\mathrm{o}}\left(\frac{\hat{\mathrm{k}}}{\mathrm{M}_{\mathrm{o}}} \mu\right) \sin ^{-1}\left(\frac{\nu}{\mu}\right)$

$+\sum_{\mathrm{r}=1}^{\infty} \frac{(-1)^{\mathrm{r}}}{\mathrm{r}} \mathrm{J}_{2 \mathrm{r}}\left(\frac{\hat{\mathrm{k}}}{\mathrm{M}_{\mathrm{o}}^{\mu}}\right) \sin \left(2 \mathrm{r} \sin ^{-1}\left(\frac{\nu}{\mu}\right)\right)$

in which $\mathrm{J}_{2 \mathrm{r}}$ is a Bessel function of even order. is given by

Using (A-6) in Eq. (5) the velocity potential influence coefficient matrix from Eqn. (11)

$$
\Phi_{i j} \quad=\frac{1}{\pi} \int_{\xi_{\ell}}^{\xi_{\mathrm{u}}} \mathrm{e}^{-\mathrm{i} \hat{\mathrm{k}}\left(\mathrm{x}_{\mathrm{i}}-\xi_{\mathrm{j}}\right)} \int_{\eta_{\ell}}^{\eta_{\mathrm{u}}} \Omega\left(\xi_{\mathrm{j}}, \eta_{\mathrm{j}}\right) \frac{\partial \psi}{\partial \nu} \partial \eta \mathrm{d} \xi
$$

Substituting from (A7) and (A8) and integrating by parts, the velocity potential becomes

$$
\begin{array}{r}
\Phi_{\mathrm{ij}}=-\frac{1}{\pi \beta} \int_{\xi_{\ell}}^{\xi_{\mathrm{u}}} \mathrm{e}^{-\hat{\mathrm{ik}}\left(\mathrm{x}_{\mathrm{i}}-\xi_{\mathrm{j}}\right)\left[\Omega\left(\xi, \eta_{\mathrm{u}}\right) \psi\left(\xi, \eta_{\mathrm{u}}\right)-\Omega\left(\xi, \eta_{\ell}\right) \psi\left(\xi, \eta_{\ell}\right)\right.} \\
\left.-\Omega_{\eta} \int_{\eta_{\ell}}^{\eta_{\mathrm{u}}} \psi(\xi, \eta) \mathrm{d} \eta\right] \mathrm{d} \xi
\end{array}
$$

The upper and lower limits of $\eta$ are given by

$$
\begin{aligned}
& \eta_{\mathrm{u}}=\mathrm{a}_{\mathrm{u}} \xi+\mathrm{b}_{\mathrm{u}} \\
& \eta_{\ell}=\mathrm{a}_{\ell} \xi+\mathrm{b}_{\ell}
\end{aligned}
$$

where $a_{u}$ and $a_{\ell}$ are slopes of the upper and lower boundary lines, (i.e. line 1-3 and line 1-2 respectively) and $b_{u}$ and $b_{\ell}$ are the corresponding constants (See Figure 14A). The initial position of each element is assumed to be the average of its $z$ coordinates if the wing is not wholly parallel to the $x$ - $y$ plane. The integrand in Eq. (A11) is analytic in the fore Mach cone region and Gaussian type numerical integrations have been employed in all cases. 


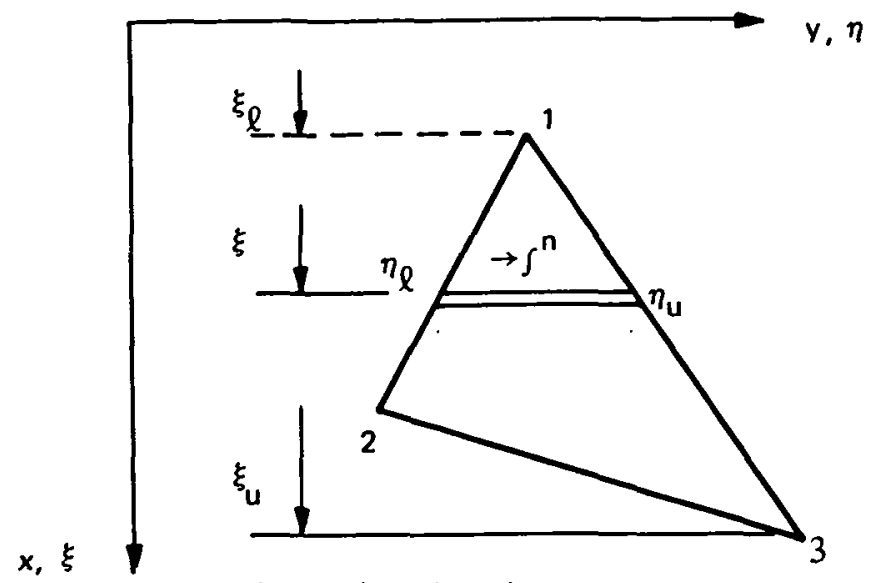

A. Integration Along $\xi$ - Axis

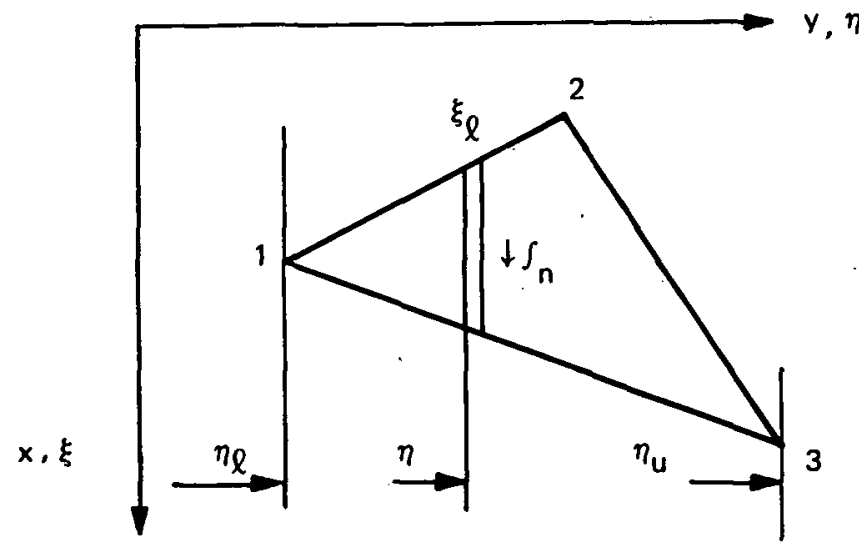

B. Integration along $\eta$ - Axis

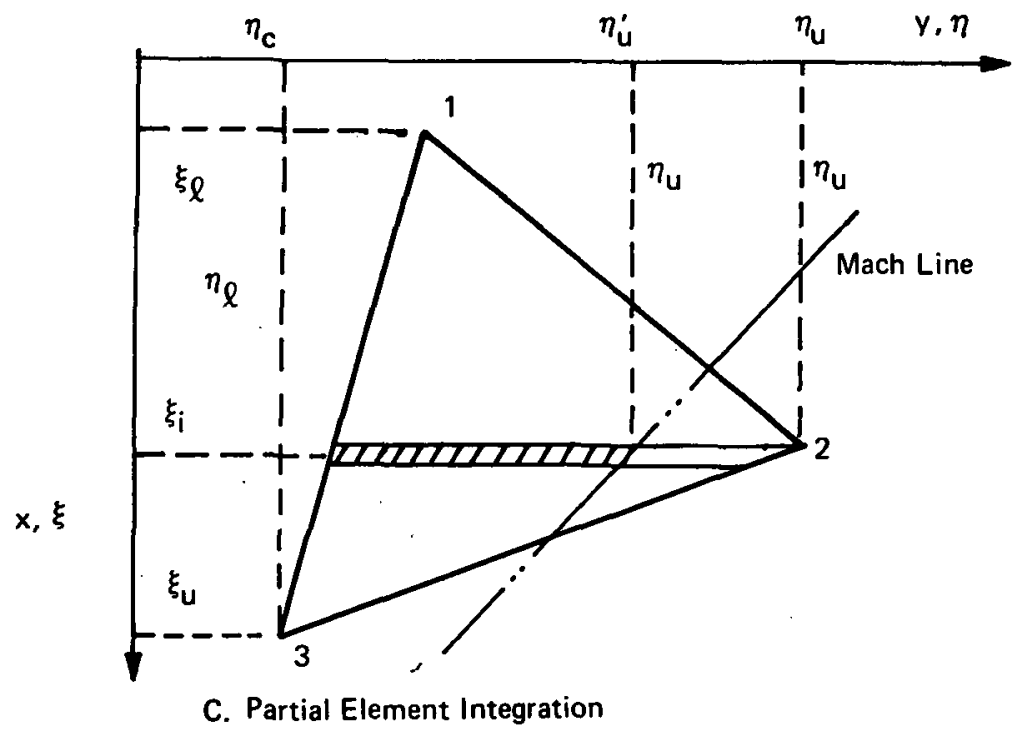

Figure 14. Integration Scheme for Triangular Elements 


\section{Downwash Integrals}

Assuming that the lifting surface is approximately parallel to the $x-y$ plane, the normal velocity at the surface is given by

$$
w e^{\lambda t}=\frac{1}{l} \frac{\partial \varphi}{\partial z} e^{\lambda t}
$$

Using Watson's relation (Eqn. (A6)) in Eqn. (4), and performing the differentiation with respect to $z$, the nondimensional downwash matrix can be written as

$$
\begin{aligned}
\mathrm{w}_{\mathrm{ij}}=-\frac{1}{\pi \beta} \int_{\xi \ell}^{\xi_{\mathrm{u}}} \mathrm{e}^{-i \hat{k}(\mathrm{x}-\xi)} & {\left[\left\{\Omega\left(\xi, \eta_{\mathrm{u}}\right) \frac{\partial \psi\left(\xi, \eta_{\mathrm{u}}\right)}{\partial \mathrm{z}}-\Omega\left(\xi, \eta_{\ell}\right) \frac{\partial \psi\left(\xi, \eta_{\ell}\right)}{\partial \mathrm{z}}\right\}\right.} \\
& \left.-\Omega_{\eta} \int_{\eta_{\ell}}^{\eta_{\mathrm{u}}} \frac{\partial \psi(\xi, \eta)}{\partial \mathrm{z}} \mathrm{d} \eta\right] \mathrm{d} \xi
\end{aligned}
$$

The derivatives in (A14) can be changed to different bases more convenient for integration purposes. From (A7)

$$
\begin{aligned}
& \frac{\partial \psi}{\partial \mathrm{z}}=\frac{\partial \psi}{\partial \mu} \quad \frac{\partial \mu}{\partial \mathrm{z}} \\
& \frac{\partial \psi}{\partial \xi}=\frac{\partial \psi}{\partial \mu} \quad \frac{\partial \mu}{\partial \xi}
\end{aligned}
$$

and therefore

$$
\frac{\partial \psi}{\partial z}=\frac{\beta^{2}(\mathrm{z}-\zeta)}{(\mathrm{x}-\xi)} \quad \frac{\partial \psi}{\partial \xi}
$$

Substituting Eqn. (A15-17) in Eqn. (A14), the downwash integral, after performing integration by parts and simplifying, becomes

$$
\mathrm{W}_{\mathrm{ij}}=\frac{-\beta(\mathrm{z}-\zeta)}{\pi}\left[\mathrm{I}_{1}-\mathrm{I}_{2}\right]
$$

where $I_{1}=\int_{\xi_{\ell}}^{\xi_{\mathrm{u}}} \frac{\mathrm{e}^{-i \hat{\mathrm{k}}(\mathrm{x}-\xi)}}{(\mathrm{x}-\xi)}\left\{\Omega_{\xi}\left(\psi\left(\xi, \eta_{\ell}\right)-\psi\left(\xi, \eta_{\mathrm{u}}\right)\right)\right.$

$$
\left.+\frac{1+i \hat{k}(x-\xi)}{(x-\xi)}\left(\Omega\left(\xi, \eta_{\ell}\right) \psi\left(\xi, \eta_{\ell}\right)-\Omega\left(\xi, \eta_{u}\right) \psi\left(\xi, \eta_{u}\right)\right)\right\} d \xi
$$


and $\quad \mathrm{I}_{2}=\Omega_{\eta} \int_{\eta_{\ell}}^{\eta_{\mathrm{u}}}\left[\left\{\frac{\mathrm{e}-\mathrm{i} \hat{\mathrm{k}}\left(\mathrm{x}-\xi_{\mathrm{u}}\right)}{\left(\mathrm{x}-\xi_{\mathrm{u}}\right)} \psi\left(\xi_{\mathrm{u}}, \eta\right)-\frac{\mathrm{e}^{-\mathrm{i} \hat{\mathrm{k}}\left(\mathrm{x}-\xi_{\ell}\right)}}{\left(\mathrm{x}-\xi_{\ell}\right)} \psi\left(\xi_{\ell}, \eta\right)\right\}\right.$

$$
\left.-\int_{\xi_{\ell}}^{\xi_{u}} \psi(\xi, \eta) \frac{\mathrm{e}^{-\hat{\mathrm{i}}(\mathrm{x}-\xi)}}{(\mathrm{x}-\xi)}\left(\frac{(1+\mathrm{i} \hat{\mathrm{k}}(\mathrm{x}-\xi)}{(\mathrm{x}-\xi)}\right) \mathrm{d} \xi\right] \mathrm{d} \eta
$$

The first two terms in $I_{1}$ vanish when taken on the boundary of the triangle. The limits of integration in $\mathrm{I}_{2}$ are as shown in Figure $14 \mathrm{~A}, \mathrm{~B}$, and $\mathrm{C}$. Since the singularities have been eliminated in these integrals the limits of integration for the elements can extend up to the Mach cone.

Numerical integration for Eqns (A11), (19) and (20) in the $\xi$ and $\eta$ senses proceed towards the element side furthest from the respective axis in all cases (See Figures 14A, B). Gaussian integration is performed for the now-analytical formulation of elements totally within and cut by the Mach cones. The limits of integration of the latter are determined by the conditions $r$ or $s=0$ as defined in Eq. (6). These limits are indicated on Figure 14C. 


\section{REFERENCES}

1. Ashley, H.; Widnall, S.; and Landahl, M.T.: New Directions in Lifting Surface Theory. AlAA J., vol. 3, no. 1, Jan. 1965, pp. 3-16.

2. Landahl, M.T.; and Stark, V.J.E.: Numerical Lifting Surface Theory-Problems and Progress. AIAA J., vol. 6, no. 11, Nov. 1968, pp. 2049-2059.

3. Garrick, I.E.; and Rubinow, S.I.: Theoretical Study of Air Forces on an Oscillating or Steady Thin Wing in a Supersonic Main Stream. NACA Report 872, 1947.

4. Pines, S.; Dugundji, J.; and Neuringer, J.: Aerodynamic Flutter Derivatives for a Flexible Wing with Supersonic and Subsonic Edges. J. Aeron. Sci., vol. 22, no. 10, Oct. 1955, pp. 693-700.

5. Smith, G.C.C.: An Approximate Numerical Method of Calculating Three-Dimensional Supersonic Flutter Derivatives for Distortion Modes of Vibration. Bristol Aeroplane Co., Tech. Office, Rept. No. 80, Mar. 1954.

6. Zartarian, G.; Hsu, P.T.; and Voss, H.M.: Application of Numerical Integration Techniques to the Low-Aspect-Ratio Flutter Problem in Subsonic and Supersonic Flows. M.I.T. Aeroelastic and Structures Research Lab. Tech. Rept. 52-3, Oct. 1954.

7. Li, T.: Aerodynamic Influence Coefficients for an Oscillating Finite Thin Wing, Part I. Chance Vought Aircraft Inc. Rept. June 1954.

8. Zartarian, G.; and Hsu, P.T.: Theoretical Studies on the Prediction of Unsteady Supersonic Airloads on Elastic Wings, Parts I and II. WADC Tech Rept. 56-97, 1955.

9. Ashley, H. : Supersonic Air Loads on Interfering Lifting Surfaces by Aerodynamic Influence Coefficient Theory. The Boeing Co. Rept. No. D2-22067, Nov. 1962.

10. Moore, M.T.; and Andrew, L.V.: Unsteady Aerodynamics for Advanced Configurations, Parts I to IV. FDL-TDR-64152, 1965.

11. Donato, V.W.; and Huhn, C.R.: Supersonic Unsteady Aerodynamics for Wings With Trailing Edge Control Surfaces and Folded Tips. AFFDL-TR-68-30, Aug. 1968.

12. Stark, V.J.E.: Calculation of Aerodynamic Forces on Two Oscillating Finite Wings at Low Supersonic Mach Numbers. SAAB TN53, Sweden 1964.

13. Appa, K.: Kinematically Consistent Unsteady Aerodynamic Coefficients in Supersonic Flow. Intl. J. for Numerical Methods in Eng'g., vol. 2, pp. 495-507, Oct. 1970. (Also National Aeronautical Laboratories NAL TN-9, India, Mar. 1968.)

14. Appa, K.; and Smith, G.C.C.: Further Developments in Consistent Unsteady Supersonic Aerodynamic Coefficients. AIAA, J. of Aircraft, vol. 9, no. 2, Feb. 1972. 
15. Richardson, J.R.: A More Realistic Method For Routine Flutter Calculations. AIAA Symp., on Structural Dynamics and Aeroelasticity, Boston, Mass., Aug. 30 - Sept. 1, 1965.

16. Hassig, H.J.: An Approximate True Damping Solution of the Flutter Equation by Determinant Iteration. J. of Aircraft, vol. 8, no. 11, p. 885, Nov. 1971.

17. Argyris, J. H.: Continua and Discontinua. Proc. Air Force Conf. Matrix Methods Structural Mechanics. Wright-Patterson AF Base, Dayton, Ohio, 1965.

18. Evvard, J.C.: Use of Source Distributions for Evaluating Theoretical Aerodynamics of Thin Finite Wings at Supersonic Speeds. NACA TR 951, 1950.

19. Olsen, J.J.: Demonstration of a Supersonic Box Method for Unsteady Aerodynamics of Nonplanar Wings, Parts I and II. FDL-TR-67-104, Feb. 1969.

20. Laschka, B.; et al: Generalized Aerodynamic Forces for Some Wing Planforms According to the Linearized Three-Dimensional Lifting Surface Theory in Subsonic and Supersonic Flow. VFW No. M-75/66, Dec. 1966. AGARD Structures and Materials Meeting. Ottawa, Sept. 1967.

21. Cunningham, H.J.: Application of a Supersonic Kernel-Function Procedure to Flutter Analysis of Thin Lifting Surfaces. NASA TN-D-6012, Nov. 1970.

22. Woodcock, D.L.; and York, E.J.: A Supersonic Box Collocation Method for The Calculation of Unsteady Air Forces of Tandem Surfaces. AGARD-CP-80-71 Part I, 1971.

23. Nelson, H.C.; Rainey, R.A.; and Watkins, C.E.: Lift and Moment Coefficients Expanded to the Seventh Power of Frequency for Oscillating Rectangular Wings in Supersonic Flow and Applied to a Specific Flutter Problem. NACA TN 3076, Apr. 1954.

24. Martin, J.C.; Diederich, M.S.; and Bobbitt, P.J.: A Theoretical Investigation of the Aerodynamics of Wing-Tail Combinations Performing Time-Dependent Motions at Supersonic Speeds. NACA TN 3072, May 1954.

25. Jones, W. P.: Supersonic Theory for Oscillating Wings of Any Planform. A.R.C R\&M 2655, Great Britain, June 1948.

26. Allen, D. J.; and Sadler, D.S.: Oscillatory Aerodynamic Forces in Linearized Supersonic Flow for Arbitrary Frequencies, Planforms and Mach Numbers. ARC R\&M 3415, Great Britain, 1963.

27. Heaslet, M.A.; Lomax, H.; and Jones, A.L.: Volterra's Solution of the Wave Equations as Applied to Three-Dimensional Supersonic Airfoil Problems. NACA Rept. No. 889, 1947.

28. Paine, A. A.: Development and Applications of Supersonic Unsteady Consistent Aerodynamics for Interfering Parallel Wings. User's Manual, Bell Aerospace Rept. No. 2471-956003. Programmer's Manual, Bell Aerospace Rept. No. 2471-956004. (Available as NASA-CR-112184 and NASA CR-112185)

29. Cunningham, H.J.: Total Lift and Pitching Moment on Thin Arrowhead Wings Oscillating in. Supersonic Potential Flow. NACA TN 3433, May 1955. 
"The aeronautical and space activities of the United States shall be conducted so as to contribute ... to the expansion of buman knowledge of phenomena in the atmosphere and space. The Administration sball provide for the widest practicable and appropriate dissemination of information concerning its activities and the results thereof."

-National Aeronautics and SpaCe ACt of 1958

\section{NASA SCIENTIFIC AND TECHNICAL PUBLICATIONS}

TECHNICAL REPORTS: Scientific and technical information considered important, complete, and a lasting contribution to existing knowledge.

TECHNICAL NOTES: Information less broad in scope but nevertheless of importance as a contribution to existing knowledge.

TECHNICAL MEMORANDUMS:

Information receiving limited distribution because of preliminary data, security classification, or other reasons. Also includes conference proceedings with either limited or unlimited distribution.

CONTRACTOR REPORTS: Scientific and technical information generated under a NASA contract or grant and considered an important contribution to existing knowledge.
TECHNICAL TRANSLATIONS: Information published in a foreign language considered to merit NASA distribution in English.

SPECIAL PUBLICATIONS: Information derived from or of value to NASA activities. Publications include final reports of major projects, monographs, data compilations, handbooks, sourcebooks, and special bibliographies.

\section{TECHNOLOGY UTILIZATION} PUBLICATIONS: Information on technology used by NASA that may be of particular interest in commercial and other non-aerospace applications. Publications include Tech Briefs, Technology Utilization Reports and Technology Surveys.

Defails on the availability of these publications may be obtained from:

SCIENTIFIC AND TECHNICAL INFORMATION OFFICE 